\title{
ESTABILIDADE OXIDATIVA DE ÓLEO DE PEIXE ENCAPSULADO E ACONDICIONADO EM DIFERENTES TIPOS \\ DE EMBALAGEM EM CONDIÇÃO AMBIENTE
}

\section{SELMA GUIDORIZZI ANTONIO PACHECO}

Dissertação apresentada à Escola Superior de Agricultura "Luiz de Queiroz", Universidade de São Paulo, para obtenção do título de Mestre em Ciências, Área de Concentração: Ciência e Tecnologia de Alimentos.

\author{
PIRACICABA \\ Estado de São Paulo - Brasil \\ Janeiro - 2005
}




\title{
ESTABILIDADE OXIDATIVA DE ÓLEO DE PEIXE ENCAPSULADO E ACONDICIONADO EM DIFERENTES TIPOS DE EMBALAGEM EM CONDIÇÃO AMBIENTE
}

\section{SELMA GUIDORIZZI ANTONIO PACHECO}

Farmacêutico - Bioquímico

Orientador: Profa ${ }^{\text {. Dra }}$. MARISA APARECIDA BISMARA REGITANO-D'ARCE

Dissertação apresentada à Escola Superior de Agricultura "Luiz de Queiroz", Universidade de São Paulo, para obtenção do título de Mestre em Ciências, Área de Concentração: Ciência e Tecnologia de Alimentos.

\author{
PIR A CICABA \\ Estado de São Paulo - Brasil \\ Janeiro - 2005
}


Dados Internacionais de Catalogação na Publicação (CIP) DIVISÃO DE BIBLIOTECA E DOCUMENTAÇÃO - ESALQ/USP

Pacheco, Selma Guidorizzi Antonio

Estabilidade oxidativa de óleo de peixe encapsulado e acondicionado em diferentes tipos de embalagem em condição ambiente / Selma Guidorizzi Antonio Pacheco. - Piracicaba, 2005.

63 p. : il.

Dissertação (Mestrado) - - Escola Superior de Agricultura Luiz de Queiroz, 2005. Bibliografia.

1. Ácidos graxos 2. Alimentos funcionais 3. Embalagens de alimentos 4. Óleos e gordura: animais 5. Oxidação 6. Peixe I. Título

CDD 665.2

"Permitida a cópia total ou parcial deste documento, desde que citada a fonte - $\mathrm{O}$ autor" 
Ao meu marido José Vitório e meus filhos Ana Luisa e Vinícius, por abrirem mão dos momentos de convivência, (por sofrerem com) a minha ausência e muitas vezes me (encontrarem) de mau humor, pelo vazio deixado quando vocês muito precisavam, meu carinho cheio de reconhecimento pelos sacrifícios. Amo Vocês. 


\section{AGRADECIMENTOS}

\section{A Deus, por tudo e por estar presente em todos os momentos da}

minha vida.

Aos meus pais, de vocês recebi o dom da vida. Vocês emprestaram-me seu amor para que eu pudesse existir: mais que isso, trabalharam, sacrificando seus sonhos em favor dos meus. Por tudo, sou infinitamente grata.

Aos meus familiares que, mesmo de longe, sempre torceram por mim.

Aos meus primos Wagner e Sandra, pelo constante apoio. Em todos os momentos vocês abriram os braços, o coração, enfim, ofereceram o ombro em todos as horas da minha jornada, ouviram meus anseios, me encorajando. Muito obrigada.

À d. Tereza e Flávia Pacheco e Maria Cecília Albaran que se doaram inteiramente aos meus filhos, para que eu pudesse chegar até aqui. Muitíssimo obrigada.

Aos Dr. Irani e Loidy Rosique, que me abriram as portas para o futuro, com a luz mais brilhante que pude encontrar: incentivo, apoio e amor ao estudo, minha eterna gratidão.

Ao Dr. Walter Accorsi e Dra. Waltterly Accorsi, minha admiração pela sua pessoa, meus agradecimentos pelo seu apoio, meu carinho pela sua amizade.

Aos meus tios Benedito e Maria Helena Paiva, que sempre estiveram comigo. É pouco pelo muito que me ajudaram, por isso meu reconhecimento e minha eterna gratidão. 
Dra. Marisa A B. Regitano d’Arce, minha orientadora: "um discípulo nunca pode imitar os passos do seu guia. Porque cada um tem a sua maneira de ver a vida, de conviver com as dificuldades e com as conquistas".

Ensinar é mostrar que é possível! Aprender é tornar possível a si mesmo.

Obrigada, com sua orientação consegui tornar possível o que me foi ensinado.

Aos professores e funcionários do Departamento de Agroindústria, Alimentos e Nutrição, especialmente Midiam e Beatriz.

Aos colegas do laboratório meus agradecimentos.

Um agradecimento especial à técnica do Laboratório de Óleos e Gorduras, Maria Fernanda de Almeida Prado e estagiária Gabriela, meu mais profundo respeito, o que será pouco diante do muito que me foi oferecido. Serei eternamente grata.

À Janaína, você que esteve presente na alegria e nas tristezas, fazendome ver nas derrotas, as vitórias; na fraqueza, uma força maior, muito obrigada.

À lara e Eloise por serem amigas sinceras e companheiras.

Ao Aelson pelo companheirismo, lealdade enteresse fraterno.

Ao Arlindo, pela incomparável solicitude, abrindo-me as portas e deixando-me totalmente segura para pesquisar e pedir orientações, minha eterna gratidão.

À Cardinal, pela cessão das cápsulas e embalagens.

À Serpac, pelos filmes PVC e PVDC e pelo serviço de emblistagem.

À Rexam, pelo fornecimento do filme PCTFE.

Ao Laboratório Fármaco Botânico Professor Walter R. Accorsi LTDA, pelo auxílio proporcionando a participação em congressos.

À Profa. Maria Imaculada Montebelo, pela análise estatística.

A todos que possa ter esquecido de citar, mas que de uma forma ou outra contribuíram para esta minha realização, com forte emoção Ihes deixo meus profundos e sinceros agradecimentos. 


\section{SUMÁRIO}

Página

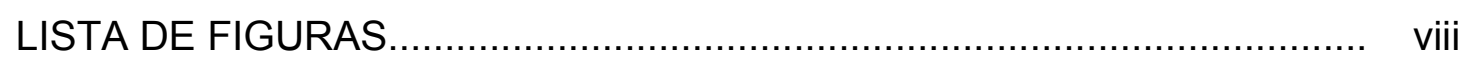

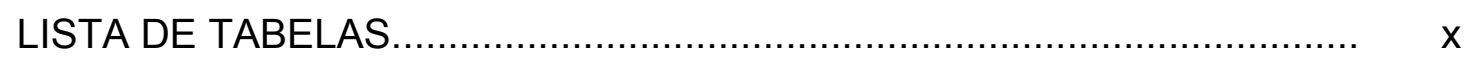

LISTA DE QUADROS ...................................................................

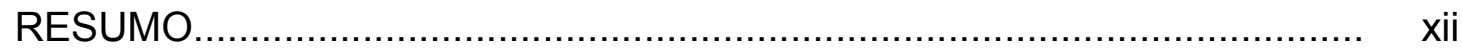

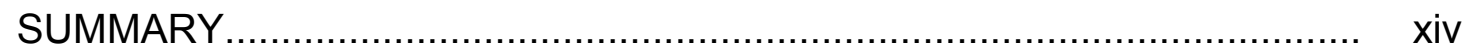

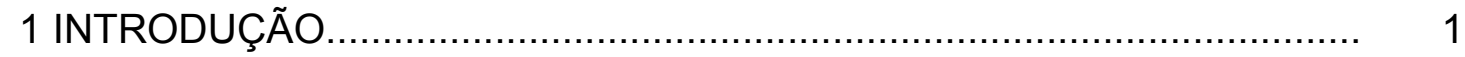

2 REVISÃO DE LITERATURA ......................................................... 3

2.1 Lipídeos e proteínas funcionais dos pescados...................................... 3

2.2 Efeito dos ácidos graxos polinsaturados $\omega-3$ no organismo humano...... 4

2.3 Processamento de óleos marinhos.................................................... 8

2.4 Oxidação de óleos.................................................................... 10

2.4.1 Rancidez oxidativa............................................................... 10

2.4.2 Toxidez dos lipídeos oxidados e suas implicações na saúde.............. 15

2.5 Métodos de análise................................................................... 15

2.5.1 Índice de peróxido..................................................................... 15

2.5.2 Espectroscopia de varredura na faixa do espectro ultravioleta.................................................................... 16

2.6 Fabricação comercial da cápsula.................................................. 18

2.6.1 Processo de fabricação .......................................................... 19

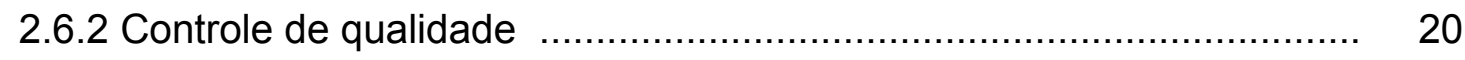

2.7 Embalagens ......................................................................... 21

2.7.1 Embalagens plásticas................................................................ 22 
2.7.1.1 Polietileno de alta densidade................................................... 23

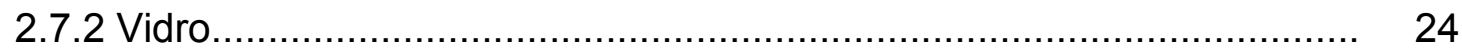

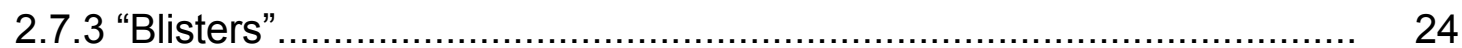

2.7.3.1 Principais componentes para formação do "blister" ......................... 25

2.7.3.2 Policloreto de vinila................................................................... 29

2.7.3.3 Cloreto de polivinilideno...................................................... 30

2.7.3.4 Policlorotrifluoroetileno.......................................................... 30

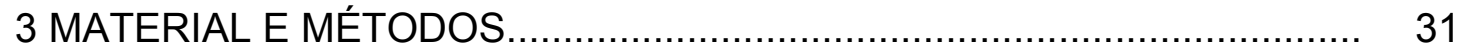

3.1 Óleo de peixe encapsulado...................................................... 31

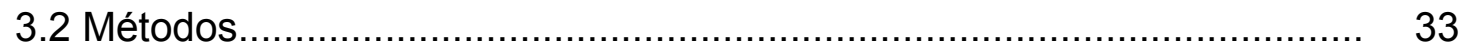

3.2.1 Análises químicas.................................................................... 33

3.2.1.1 Ácidos graxos livres.......................................................... 33

3.2.1.2 Índice de peróxido.................................................................... 33

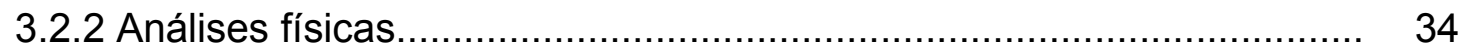

3.2.2.1 Absortividade em 232 e 270 nm................................................ 34

3.2.2.2 Espectro de absortividade na faixa do espectro ultravioleta - 220 a

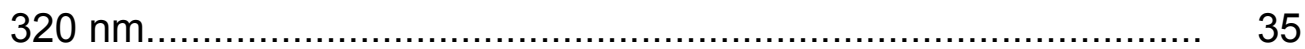

3.2.2.3 Cromatografia gasosa....................................................... 35

3.3 Experimento …................................................................. 35

3.3.1 Armazenamento ao ambiente ................................................... 35

3.3.2 Análise estatística................................................................. 36

4 RESULTADOS E DISCUSSÃO..................................................... 37

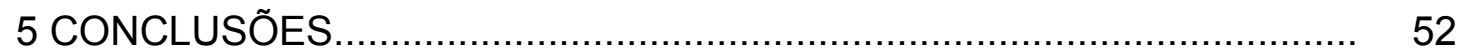

REFERÊNCIAS BIBLIOGRÁFICAS ................................................. 53 


\section{LISTA DE FIGURAS}

Página

1 Relação metabólica dos ácidos graxos poliinsaturados das

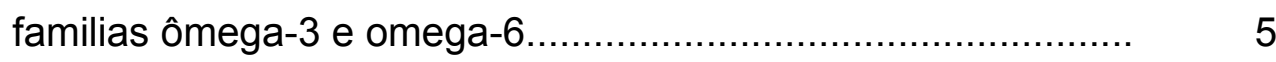

2 Metabolismo dos ácidos graxos poliinsaturados fornecidos pela dieta.

3 Processo de fabricação e extração do óleo de peixe.

$4 \quad$ Mecanismo da autoxidação de lipídeos.................................... 12

$5 \quad$ Processo de fabricação do "blister" ........................................... 26

6 Diferentes zonas climáticas na Comunidade Européia............ 27

$7 \quad$ Cápsulas gelatinosas de óleo de peixe............................... 31

$8 \quad$ Embalagens utilizadas no experimento..................................... 32

9 Acidez (\% ácido oléico) do óleos de peixe encapsulado e acondicionado em diferentes tipos de embalagem por 12 meses.

10 Índice de peróxido (meq $\mathrm{O}_{2} / \mathrm{kg}$ de óleo) do óleo de peixe encapsulado e acondicionado em diferentes tipos de embalagem por 12 meses...

11 Absortividade em $232 \mathrm{~nm}$ no óleo de peixe encapsulado e acondicionado em diferentes tipos de embalagem por 12 meses. 
12 Absortividade em $270 \mathrm{~nm}$ do óleo de peixe encapsulado e acondicionado em diferentes tipos de embalagem por 12

13 Espectros de absortividade na faixa do ultravioleta do óleo de peixe encapsulado e acondicionado em diferentes tipos de embalagem por 3 (a) e 6(b) meses, 9(c) meses e 12(d) meses

14 Concentração de ácido eicosapentaenóico (\%) (a) e docosahexaenóico (\%) (b) do óleo de peixe encapsulado e acondicionado em diferentes tipos de embalagem por 12 meses. 


\section{LISTA DE TABELAS}

Página

1 Temperatura e umidade relativa ambiente do local do armazenamento das cápsulas durante 0 período experimental

2 Índice de peróxido (meq $\mathrm{O}_{2} / \mathrm{kg}$ de óleo) do óleo de peixe encapsulado e acondicionado em diferentes tipos de embalagem por 12 meses.

3 Absortividade em $232 \mathrm{~nm}$ do óleo de peixe encapsulado e acondicionado em diferentes tipos de embalagem por 12 meses.

4 Absortividade em $270 \mathrm{~nm}$ do óleo de peixe encapsulado e acondicionado em diferentes tipos de embalagem por 12 meses. 


\section{LISTA DE QUADROS}

1 Porcentagem de ácidos graxos em certas espécies de óleo de peixe.

2 Compostos da oxidação lipídica e suas respectivas faixas de absorção no espectro do ultravioleta...

3 Classificação do uso da gelatina quanto ao "bloom" na fabricação de cápsulas.

4 Embalagens utilizadas para produtos farmacêuticos.

5 Materiais para a formação dos "blisters" e sua adequação conforme as zonas climáticas. 


\title{
ESTABILIDADE OXIDATIVA DE ÓLEO DE PEIXE ENCAPSULADO E ACONDICIONADO EM DIFERENTES TIPOS DE EMBALAGEM EM CONDIÇÃO AMBIENTE
}

\author{
Autor: SELMA GUIDORIZZI ANTONIO PACHECO \\ Orientadora: Profa ${ }^{a}$. Dra ${ }^{a}$. MARISA APARECIDA BISMARA REGITANO-D'ARCE
}

\section{RESUMO}

Tem havido um avanço em pesquisas de produtos marinhos, especialmente devido à presença de ácidos graxos poliinsaturados (AGPI), eicosapentanóico (EPA) e docosahexaenóico (DHA), que são abundantes em óleos de peixe e contribuem para a redução dos índices de triacilglicerol e colesterol no sangue. Contudo, os ácidos graxos poliinsaturados são propensos à oxidação. Quanto maior o grau de insaturação do óleo, menos estável ele é, podendo ocorrer comprometimento das duplas ligações devido à oxidação. Essa pesquisa teve como objetivo estudar a estabilidade de óleo de peixe encapsulado acondicionado em diferentes tipos de embalagens. $O$ óleo utilizado nesse experimento foi cedido pela indústria farmacêutica Cardinal Health Brasil, já refinado e em cápsulas gelatinosas moles. Após a encapsulação, a metade dessas cápsulas foi enviada à Empresa SERPAC Comércio e Indústria Ltda. para o processo de emblistagem, em que foram utilizados os filmes policlorotrifluoroetileno (PCTFE), comercializado sob o nome Aclar Rx $160(15 \mu)$, cloreto de polivinilideno (PVDC-60 $\mathrm{gsm}^{2}$ ) e policloreto de 
vinila (PVC-250 $\mu$ ) e, posteriormente, acondicionados em caixas de papel cartonado. O restante foi acondicionado em frascos de polietileno de alta densidade (PEAD) com e sem sachês de sílica e em vidro de cor âmbar. Cada frasco ou embalagem cartonada contendo 60 cápsulas foi armazenado em triplicata sob temperatura ambiente e o óleo analisado a cada 28 dias por um período de 12 meses. As análises realizadas mensalmente no óleo foram a determinação da acidez, do índice de peróxido e da absortividade em 232 e 270nm. A composição em ácidos graxos por cromatografia gasosa, especialmente os teores de EPA e DHA, foi determinada no início, aos 3, 6 e 12 meses. A embalagem em que o óleo apresentou as maiores alterações foi o blister de filme PVC. O melhor desempenho foi encontrado no óleo encapsulado, acondicionado na embalagem de PEAD com dessecante de sílica. Os teores de DHA e EPA mantiveram-se estáveis até o sexto período, ocorrendo uma queda considerável no décimo segundo período no óleo da embalagem do filme PCTFE, devido provavelmente a problemas de a termosoldagem e selagem. 
OXIDATIVE STABILITY OF ENCAPSULATED FISH OIL STORED IN DIFFERENT TYPES OF PACKING UNDER AMBIENT CONDITIONS

\author{
Author: SELMA GUIDORIZZI ANTONIO PACHECO \\ Adviser: Prof ${ }^{a}$. Dra . MARISA APARECIDA BISMARA REGITANO-D'ARCE
}

\title{
SUMMARY
}

Due to the presence of long chained omega three fatty acids, fish oils have gathered much interest recently. Fish oils are a rich source of polyunsaturated fatty acids (PUFA) like eicosapentaenoic acid (EPA) and docosahexaenoic acid (DHA), which reduce blood triacylglycerol and cholesterol levels. However, the higher the unsaturation level, the less stable is the oil which may have its double links compromised due to oxidation. This research main interest was the stability of encapsulated fish oil, stored in different types of packagings. The fish oil used in this experiment was supplied by Cardinal Pharmaceutical Industry in soft gel capsules. After encapsulation, half of the samples were sent to SERPAC Industry LTDA for blistering, where polychlortrifluoroethylene (PCTFE), commercially known as Aclar Rx $160(15 \mu)$, polyvinyldichloride (PVDC-60 gsm $^{2}$ ) and polyvinylchoride (PVC-250 $\mu$ ) films were used as three of the treatments. Blisters were packed in carton boxes. The other half of the capsules was packed in amber glass or high density polyethylene (PEAD) rigid flasks with and without silica bags. Each treatment contained 60 capsules in triplicate and all packs were stored under ambient conditions for 12 
months. Analytical determinations were performed on the oil every 28 days and included acid and peroxide values, and absortivities in the ultraviolet region at 232 and $270 \mathrm{~nm}$. Fatty acid composition determinations, especifically EPA and DHA content were performed at the beginning of the experiment, after 3,6 and 12 months. The package, which presented the largest changes in quality of the oil, was the PVC film "blister". The best results were found in encapsulated oil stored in PEAD flasks with silica bags. EPA and DHA contents were kept constant until the sixth period of storage for all samples. The largest changes happened in the oil stored in PCTFE films, with a drastic reduction on the $12^{\text {th }}$ period due, probably to problems in thermomolding and sealing. 


\section{INTRODUÇÃO}

Estudos evidenciam que gorduras oxidadas e produtos de peroxidação lipídica na dieta podem contribuir para o aparecimento de doenças, uma vez que estes compostos são absorvidos pelo intestino e transportados pela corrente sangüínea. Além disso, os produtos de peroxidação lipídica podem irritar o intestino levando à diarréia e podem atuar como indutores da carcinogênese.

Pesquisas recentes tem mostrado a importância do consumo de óleo de peixe rico em ácidos graxos ômega-3, principalmente ácido eicosapentaenóico (EPA) e ácido docosahexaenóico (DHA) devido à possibilidade de se promover redução da concentração de lipoproteínas de baixa densidade (LDL) circulantes e conseqüentemente prevenir doenças cardiovasculares. Também atuam na prevenção da tumorogênese de mama, cólon e de próstata (Lands, 1986; Reddy \& Maruyama, 1986).

Os óleos de peixes são muito susceptíveis a processos oxidativos. Isto ocorre por possuírem várias insaturações em sua cadeia carbônica. Os processos oxidativos comprometem a integridade das duplas ligações e a concentração e funcionalidade dos ácidos graxos EPA e DHA, além de colocarem em risco a saúde humana. Para evitar os processos peroxidativos a embalagem utilizada deve apresentar boa barreira ao oxigênio, à umidade e às radiações luminosas. Quanto mais insaturações possuírem os lipídeos, maior deverá ser a proteção da embalagem. As embalagens para produtos farmacêuticos devem garantir a proteção do conteúdo, e a sua identificação, 
além da informação sobre a maneira correta de utilização e da facilidade e segurança no manuseio. Sabe-se que o tipo de embalagem pode influenciar na qualidade final do produto, e que este afeta diretamente a saúde do consumidor. Atualmente o filme mais utilizado comercialmente, nos blisters para cápsulas é o cloreto de polivinila, conhecido pela sigla PVC. Dada a inexistência de estudos do comportamento dos óleos encapsulados durante a comercialização e o tipo de proteção que as embalagens oferecem, propôs-se esta pesquisa cujo objetivo foi o estudo da estabilidade oxidativa do óleo de peixe ao longo de um ano de armazenamento sob condições de comercialização. 


\section{REVISÃO DE LITERATURA}

\subsection{Lipídeos e proteínas funcionais dos pescados}

De acordo com Shahidi (1998), nos anos recentes houve um grande avanço em pesquisas de produtos marinhos. Os pescados são importantes fontes de proteínas e lipídeos de origem marinha desde o início da civilização. A vantagem das proteínas dos pescados é que estas contêm uma composição de aminoácidos equilibrada. Além disso, é cada vez mais crescente o interesse nos lipídeos marinhos, dadas as concentrações de ácidos graxos polinsaturados $\varpi-3$ de cadeia longa.

Dyerberg \& Bang (1995) e Lossonczy (1978) relataram que os ácidos graxos polinsaturados (AGPI) longos, e particularmente abundantes em óleos de peixe, atualmente estão atraindo muita atenção, devido a estudos epidemiológicos realizados no norte da Groenlândia que mostraram que o EPA, um ácido graxo que predomina nos lípides do plasma de esquimós, está ligado aos baixos índices de doenças coronárias nessa população. Isso tem justificado, a suplementação de dietas ocidentais com AGPI (Kinsella, 1986), apesar do constante questionamento de que os AGPI são rapidamente oxidados e os produtos resultantes de oxidação apresentam um aspecto tóxico para saúde (Andrews et al., 1960; Halliwel \& Chirico, 1993).

O óleo de peixe, que sofreu deterioração oxidativa, contém produtos potencialmente tóxicos resultantes da peroxidação de ácidos graxos ômega-3 
que podem atuar na carcinogênese e inibir a produção de prostaciclinas (Shukla \& Perkins,1991).

\subsection{Efeitos dos ácidos graxos polinsaturados $\varpi-3$ no organismo humano}

O homem, assim como outros animais, são capazes de sintetizar certos ácidos graxos saturados e insaturados, mas não sintetizam os ácidos graxos polinsaturados, linoléico e linolênico, sendo estes essenciais ao ser humano e somente adquiridos através da alimentação (Spector, 1999). Os vegetais e algas marinhas são fontes primárias desses ácidos graxos (Cohen et al., 1995; Ahmad, 1998). No organismo, esses ácidos graxos são metabolizados a compostos importantíssimos (Figura 1).

Shahidi (1998) atribuiu os efeitos benéficos dos ácidos graxos poiinsaturados ômega-3 à saúde, à sua capacidade de reduzir os níveis de triacilglicerol e colesterol no sangue. Os lipídeos marinhos são formados no fígado, em pescados brancos e magros e na massa corporal de peixes gordurosos. Estes lipídeos são formados por ácidos graxos polinsaturados (AGPI) e também por ácidos graxos saturados e monoinsaturados. Existem dois tipos de AGPI, classificados como ômega-3 e ômega-6, e a diferença está no número e posição das duplas a partir do carbono metilênico, presente na posição terminal da molécula de ácido graxo. 
(a)

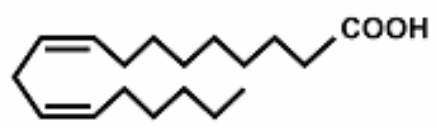

ácido linoléico

[ $\left.\mathrm{C}_{18: 2(0 \cdot 5)}\right]$

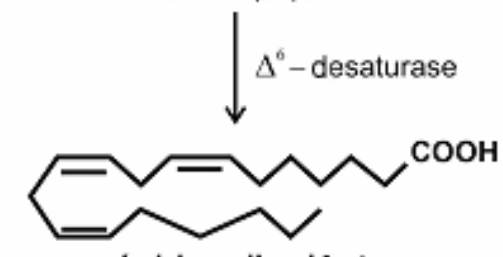

ácido $\gamma$-linolênico

[ $\left.\mathrm{C}_{18: 3(1-6)}\right]$

$\mathrm{PGE}_{1} \diamond$ ácido dihomo $\gamma$-linolênico

[ $\left.\mathrm{C}_{18: 3(1-6) 6}\right]$<smiles>[Tl]</smiles>

$\mathrm{PGE}_{1} \hookleftarrow$ ácido araquidônico (AA)

$\left[\mathrm{C}_{20: 4(0,-6)}\right]$

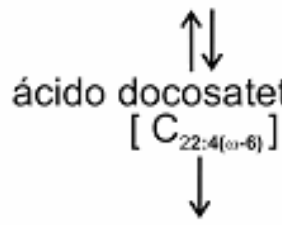

ácido docosapentaenóico

$\left[\mathrm{C}_{22: 5[(6)}\right]$ (b)

série $\omega-3$

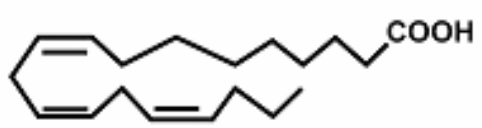

ácido $\alpha$-linolênico

[ $\left.\mathrm{C}_{18: 3(0 \cdot-3)}\right]$

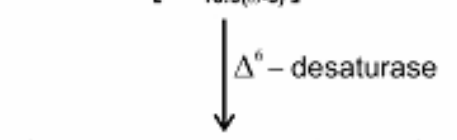

ácido octadecatetraenóico

$\left[\mathrm{C}_{18: 4(w-3)}\right]$

ácido eicosatetraenóico

[ $\left.\mathrm{C}_{20: 4(1(1-3)}\right]$<smiles>[CH]C[Tl]</smiles>

$\mathrm{PGE}_{3} \diamond$ ácido eicosapentaenóico (EPA)

$\left[\mathrm{C}_{20: 5(10-3)}\right]$

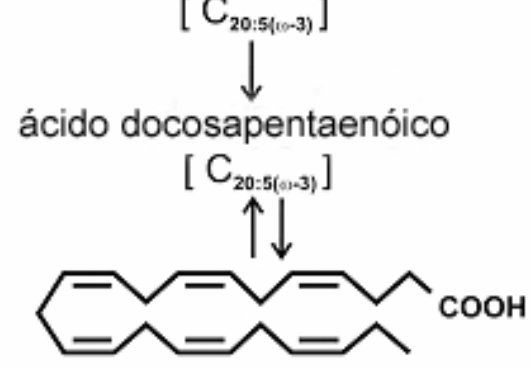

ácido docosahexaenóico (DHA)

$\left[\mathrm{C}_{22: 6(\mathrm{~m}-3)}\right]$

Figura 1 - Relação metabólica dos ácidos graxos polinsaturados das famílias ômega-6 e ômega-3

Fonte: Linko \& Hayakawa (1996)

Muitas pesquisas têm estabelecido que os ácidos graxos polinsaturados (n-3 AGPI), em particular o ácido eicosapentanóico (EPA) e o ácido docosahexanóico (DHA), são os principais componentes biologicamente ativos de óleos de peixe (Lands, 1986; Simopoulas et al., 1986). Estes componentes variam muito entre as espécies de peixes e frutos do mar (Kinsella, 1987). Alguns peixes, especialmente os gordurosos tais como 
arenque, cavala e bacalhau são espécies utilizadas para produção de óleo de peixe, com predominância de ácidos graxos polinsaturados da família ômega-3, especialmente os ácidos eicosapentaenóico (C20:5, n-3) e docosahexaenóico (22:6, n-3), como pode ser observado no Quadro 1.

\begin{tabular}{|lllll|}
\hline & C 20:4, & C 20:5, & C 22:5 & C 22:6 \\
& $n-6$ & $n-3$ & $n-3$ & $n-3$ \\
Arenque & 0,4 & 8,6 & 1,3 & 7,6 \\
Cavala & 3,9 & 7,1 & 1,2 & 10,8 \\
Bacalhau & $3,2-3,7$ & $12,4-17,6$ & $0,6-0,9$ & $21,9-37,5$ \\
\hline
\end{tabular}

Quadro 1 - Porcentagem de ácidos graxos em certas espécies de óleo de peixe Fonte: Bang \& Dyeberg (1981)

Os seus efeitos em diversas e diferentes patologias podem ser explicados pela ação na síntese e metabolismo dos eicosanóides, importantes mediadores de sinais celulares derivados de ácidos graxos de 20 carbonos, com 4 ou 5 insaturações (Lands, 1986), que culmina com a síntese de prostaglandinas, tromboxanas, prostaciclinas e leucotrienos (Figura 2). 


\section{Dietas com ácidos graxos polinsaturados}

\section{Óleos de Peixe}

Ricos em ácidos graxos ômega-3

EPA (20:5), DHA (22:6)

\section{Óleos Vegetais}

Ricos em ácidos graxos ômega-6

Linoléico (18:2)

Pequena quantidade de ácidos graxos omega-3 Linolênico (18:3)

Os ácidos graxos são incorporados em membranas fosfolipídicas de plaquetas, vasos sangüíneos, células endoteliais e outras células

Liberação de ácidos graxos de membranas. Os ácidos graxos ômega-3 competem com outros ácidos graxos polinsaturados para síntese de diferentes produtos. Sua presença reduz a produção de substâncias coagulantes.

\section{Síntese de Prostanóides}

Estes regulam atividades bioquímicas em plaquetas, células endoteliais de vasos sanguineos, outras células sanguíneas e tecidos.

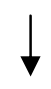

Prostaglandinas Diferentes tipos de efeitos nos tecidos
Tromboxanas Promovem formação de coágulo no sangue
Prostaciclinas

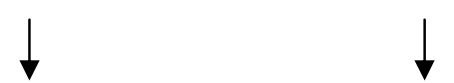

Reduzem a formação de Afetam os neutrófilos coágulo no sangue

Figura 2 - Metabolismo dos ácidos graxos poliinsaturados fornecidos pela dieta Fonte: Ahmad (1998)

Os efeitos benéficos dos lipídeos de peixe são consistentes e de considerável importância à saúde pública. Os óleos de peixe e de frutos marinhos oferecem um meio relativamente seguro e prático na prevenção ou melhora de doenças como artrite, câncer, doenças coronárias isquêmicas e processos inflamatórios e nas lesões de psoríases (Kinsella, 1986; Kremer et 
al.,1985; Kinsella,1987; Ziboh et al.,1986; Kinsella et al.,1990; Sellmayer et al.,1999 ; Kang \& Leaf,1996).

A aterosclerose é uma das mais sérias doenças cardiovasculares e uma das maiores causas de morte no mundo ocidental, diretamente relacionada com a quantidade e a qualidade das gorduras na dieta, alterando os níveis de lipoproteínas de baixa densidade (LDL) e de lipoproteínas de alta densidade (HDL) (Ahmad,1998).

Illiingworth \& Ullman (1990) propuseram que consumo de lipídeos de origem marinha provoca uma diminuição do conteúdo de lipídeos no plasma, por haver uma redução da síntese de ácidos graxos e de lipoproteínas de baixa densidade (LDL).

Estudos realizados por Strom \& Jensen (1951) durante a Segunda Guerra Mundial apontam para uma queda na mortalidade causada por doenças circulatórias e em infartos do miocárdio devido ao consumo reduzido de gorduras e um aumento no consumo de peixe, levando a uma diminuição dos níveis de colesterol no sangue. Isto é atribuído particularmente aos altos níveis de ácidos graxos polinsaturados $\omega$-3 presentes nos peixes de águas profundas e geladas.

\subsection{Processamento de óleos marinhos}

Independentemente da espécie do peixe disponível, cuja oferta é sazonal, o óleo de peixe é extraído com aplicação de vapor, para a liberação do óleo dos tecidos. Após a obtenção do óleo bruto, promove-se o processo de refino, semelhante ao dos óleos vegetais. Bimbo \& Crowther (1991) relatou que a qualidade dos óleos marinhos brutos é menos uniforme do que a dos óleos vegetais brutos e é necessário um cuidado maior na manipulação da matéria prima. 
Durante o processamento (Figura 3), deve-se procurar proteger os óleos marinhos das altas temperaturas e condições que favoreçam a sua oxidação.

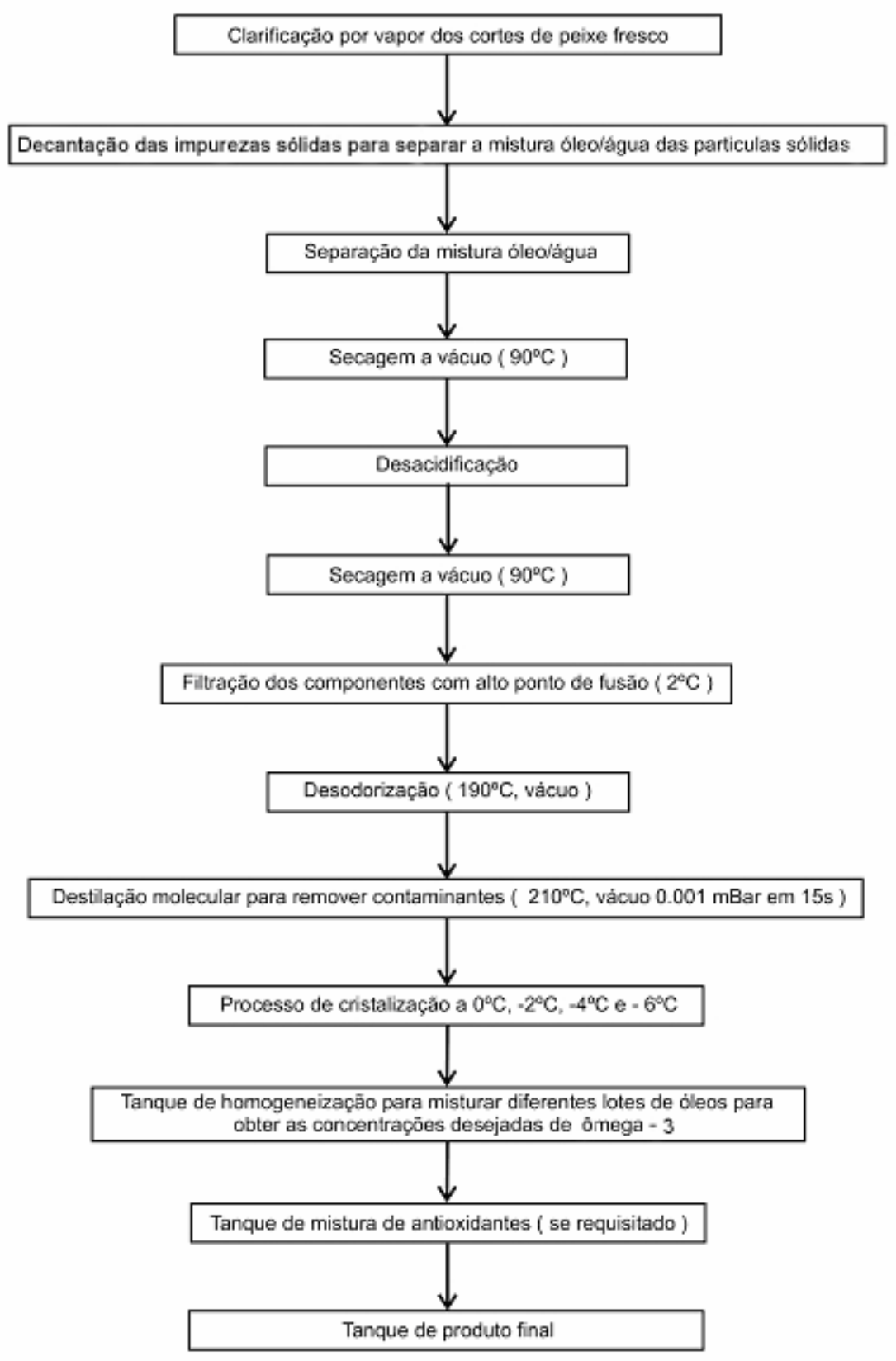

Figura 3 - Processo de fabricação e extração do óleo de peixe Fonte: Cardinal Health Brasil 


\subsection{Oxidação de óleos}

Durante o armazenamento e o processamento do óleo, este pode sofrer transformações químicas como a hidrólise e a oxidação, afetando a qualidade do óleo, decorrente dos processos oxidativos, bem como sua aceitação pelo consumidor, com conseqüente prejuízo à saúde do consumidor devido aos efeitos tóxicos causados pela ingestão contínua e prolongada de produtos oxidados (Bobbio \& Bobbio, 1992).

A estabilidade oxidativa depende do grau de insaturação dos ácidos graxos presentes, daí óleos que contenham altas proporções de ácidos graxos polinsaturados apresentarem problemas de conservação.

\subsubsection{Rancidez oxidativa}

A rancificação oxidativa ocorre normalmente com ácidos graxos insaturados, pois com ácidos graxos saturados a formação do radical livre é energeticamente desfavorável (Bobbio \& Bobbio, 1992).

A autoxidação pode ser iniciada por espécies endógenas $\left(\mathrm{H}_{2} \mathrm{O}_{2}\right.$, $\mathrm{ROOH})$ e radicais $\left(\mathrm{O}_{2}{ }^{-}, \mathrm{ROO}, \mathrm{OH}, \mathrm{GS}\right)$ ou por espécies exógenas $\left({ }^{1} \mathrm{O}_{2}, \mathrm{O}_{3}\right)$, radicais $\left(\mathrm{NO}_{x}, \mathrm{SO}_{3}{ }^{-}\right)$, e agentes (UV, radiações ionizantes, calor) (Simic et al., 1992). Entretanto, este início ainda não está completamente explicado, mas o modelo prevê a formação de radicais livres no carbono alílico. Este radical formado pode reagir com o oxigênio atmosférico e formar um radical peróxido (Bobbio \& Bobbio, 1992).

Os óleos ricos em ácidos graxos polinsaturados têm facilidade de sofrer deterioração oxidativa e formam facilmente sabores e odores desagradáveis. A inibição da oxidação é de extrema importância no processamento de óleos marinhos (Shahidi, 1998). 
A oxidação dos óleos marinhos acontece através da reação em cadeia de radicais livres em três etapas: de iniciação, propagação e terminação.

A oxidação começa com a supressão de um átomo de hidrogênio do carbono adjacente à dupla ligação do ácido graxo. O radical alquila resultante reage com o oxigênio atmosférico formando um radical livre instável peroxila. Este radical peroxila inicia a nova seqüência, abstraindo um hidrogênio da segunda molécula de ácido graxo insaturado produzindo um hidroperóxido contribuindo para a reação em cadeia. A reação em cadeia termina quando da formação de produtos não-radicais (RR, ROOR) (Figura 4).

Os peróxidos são produtos de oxidação primária, são compostos tóxicos e instáveis e degradam em produtos secundários tais como malonaldeído e 4-hidroxinonal, que são também altamente tóxicos. Os produtos de oxidação secundária são os responsáveis pelo desenvolvimento de sabor desagradável em óleos marinhos estocados (Shahidi, 1998). Os produtos de quebra da reação a partir dos hidroperóxidos são carbonilas, cetonas, aldeídos, hidrocarbonetos, álcoois, ácidos carboxílicos e outros, e são de baixo peso molecular. Em experimento realizado em laboratório observou-se que durante a oxidação de óleos ricos em AGPI do tipo ômega-3 grandes quantidades de propanal foram formados. Os produtos da quebra de hidroperóxidos, como álcoois, aldeídos, cetonas e hidrocarbonetos geralmente possuem intenso aroma desagradável (Shahidi, 1995). 


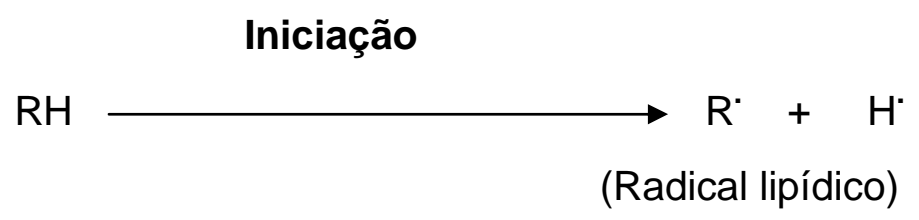

\section{Propagação}

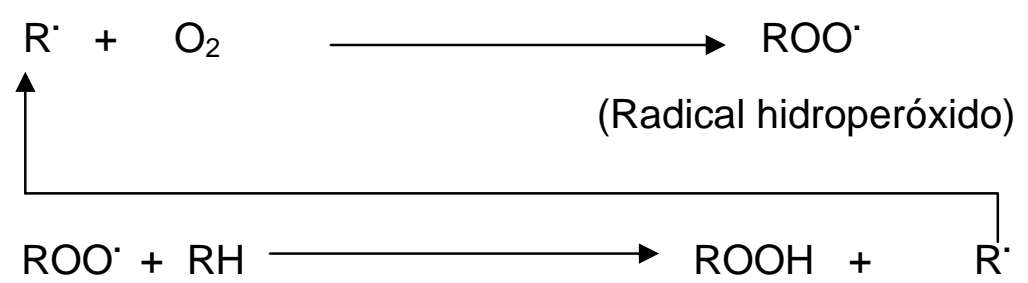

(Hidroperóxido lipídico)

\section{Terminação}

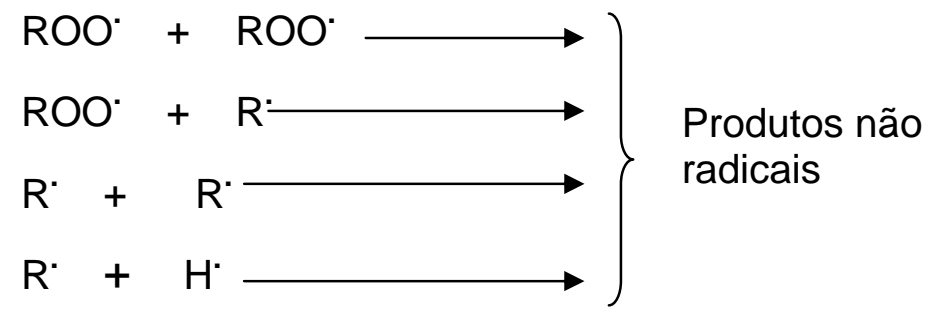

Figura 4 - Mecanismo da autoxidação de lipídeos

Fonte: Farmer et al. (1943)

A deterioração dos lipídeos pode ocorrer em reações com oxigênio atmosférico e reações hidrolíticas catalisadas por enzimas. Os efeitos das reações hidrolíticas podem ser minimizados com estocagem a frio e cuidados no transporte, na embalagem e no processamento, entretanto a oxidação, uma vez iniciada, continua ocorrendo durante o armazenamento mesmo a temperaturas baixas. Isto ocorre porque a autoxidação é uma reação química 
que necessita de baixa energia de ativação (4-5 kcal.mol $\left.{ }^{-1}\right)$ tanto para o seu início como para sua continuação (6-14 kcal.mol ${ }^{-1}$ ) (Hamilton, 1994).

$O$ radical alquila $R \cdot$ tem sua vida útil aumentada devido a formas de ressonância que o estabilizam. Estes peróxidos formados podem participar de reações de decomposição e formação de novos radicais livres (Bobbio \& Bobbio, 1992).

Esta fase de propagação leva ao aumento do número de radicais livres presentes. Estes radicais são rapidamente formados e reagem entre si na fase terminal (Bobbio \& Bobbio, 1992).

Além disso, dependendo da molécula envolvida, a oxidação pode se dar mais rapidamente, como no caso do EPA e do DHA. Segundo Cho et al. (1987), tanto o ácido eicosapentaenóico (EPA) quanto o ácido docosahexaenóico (DHA) foram oxidados, durante um ensaio de autoxidação no escuro a $5^{\circ} \mathrm{C}$, após um período de indução de 3-4 dias. Já o linolenato levou 3 semanas para oxidar e o linoleato 50 dias, sob as mesmas condições. Em relação ao consumo de oxigênio, os ésteres de EPA e de DHA foram 5,2 e 8,5 vezes, respectivamente, mais rápidos que o éster de linolenato.

De acordo com Rovellini et al. (1997), isso ocorre porque a velocidade de oxidação de compostos com sistemas polinsaturados e compostos metilênicos é muito mais alta do que os compostos que apresentam somente uma dupla ligação, já que este grupamento metilênico é ativado pelas duas duplas ligações adjacentes, aumentando assim a velocidade de reação da oxidação. Deste modo, compostos como os ésteres de DHA (6 duplas ligações) e de EPA (5 duplas ligações) obviamente terão a velocidade de reação da oxidação maior do que a dos ésteres de linoleato (com duas duplas ligações) e do que a do linolenato (com 3 duplas ligações).

Segundo Shukla \& Perkins (1991), produtos de alto peso molecular derivados tanto de oxidação térmica quanto autoxidação foram formados durante o armazenamento de óleo de peixe encapsulado em cápsulas de gelatina mole, adicionados de 164 a $7.965 \mathrm{mg} / \mathrm{g}$ de tocoferol, tanto pelas altas 
temperaturas da desodorização como resultado da autoxidação ocorrida anteriormente ao encapsulamento. Além disso, estes também podem ter-se formado após o encapsulamento, já que as cápsulas de gelatina mole mostraram ser relativamente permeáveis ao oxigênio. Como a concentração de plastificante do invólucro e as condições de armazenamento têm efeito sobre a estabilidade do óleo, uma parte da autoxidação deve ter ocorrido dentro da cápsula. Some-se a isto, o fato de os tocoferóis serem antioxidantes pobres para óleos alimentícios, principalmente os que contêm ácidos graxos polinsaturados, e de apresentarem ação pró-oxidante dependendo da concentração presente no óleo.

De acordo com Ackman (1988), o tocoferol e os carotenóides são os antioxidantes naturais presentes em peixes e moluscos. A concentração de $\alpha$ tocoferol presente é de cerca de $300 \mu \mathrm{g} / \mathrm{g}$, sendo este quase que o único isômero do tocoferol presente e o mais biopotente no homem.

Shukla \& Perkins (1991) também verificaram que materiais de alto peso molecular presentes são provavelmente compostos polímeros de triacilgliceróis ligados via pontes peróxi, e o seu aquecimento levaria ao rompimento destas e à formação tanto de produtos voláteis quanto não voláteis.

$\mathrm{Na}$ ausência de luz, o estresse térmico produz uma variedade de substâncias de alto peso molecular, descritas como dímeros, trímeros e oligômeros de triacilgliceróis. Em óleos de peixe encapsulados, de dezesseis amostras, Ackman et al. (1989) encontraram dez amostras com níveis significantes de substâncias definidas como polímeros.

Durante o estresse oxidativo, há formação de frações polares e não polares no óleo. Segundo Shukla \& Perkins (1991), a fração não polar parece conter somente polímeros de triacilgliceróis. Nesta fração apolar, as substâncias de alto peso molecular provavelmente são compostas de triacilgliceróis ligados via pontes de peróxidos. O aquecimento do óleo leva à destruição destas ligações e à formação de produtos de degradação voláteis e não voláteis. 
Para que uma maior estabilidade seja alcançada, deve-se tomar extremo cuidado no manuseio de óleos de peixe, sendo recomendada a proteção com cápsula de gelatina mole, que deve ser feita com baixa concentração de plastificante, além da estabilização com antioxidante, e devem ser estocados em lugar seco e frio (Shukla \& Perkins, 1998).

Durante a desodorização de óleos contendo ácidos graxos ômega-3, pequenas quantidades de ar (traços) favorecem o desenvolvimento de polímeros térmicos, polímeros oxidativos e polímeros térmicos oxidativos. Além disso, polímeros que são comumente chamados de "intrapolímeros" podem ser formados entre ácidos graxos de uma mesma molécula de triacilglicerol (Shukla \& Perkins, 1998).

\subsubsection{Toxidez dos lipídeos oxidados e suas implicações na saúde}

Estudos demonstraram que todas as células são expostas ao ataque de radicais livres. Caso não controlados desses agentes podem danificar os componentes celulares, tais como lipídeos de membranas, proteínas e DNA. A peroxidação de tecidos lipidicos pode romper membranas, alterar as funções das plaquetas, modificar a função dos macrófagos, alterar o ácido araquidônico, causar polimerização das proteínas e promover aterogênese através da peroxidação do LDL, além de provocar uma mutação do DNA (Kinsella et al., 1993; Eder, 1999).

\subsection{Métodos de análise}

\subsection{1 Índice de peróxido}

Muitos métodos têm sido utilizados para avaliar a qualidade dos óleos. O grau de oxidação de um óleo pode ser avaliado por vários métodos. A rancidez é uma alteração conseqüente da oxidação. $O$ índice de peróxido é o 
método mais comum para determinar o estado oxidativo de óleos e gorduras e através do índice de peróxido pode quantificar os hidroperóxidos que são os principais produtos primários da oxidação, porém, seu uso é limitado aos estágios iniciais da oxidação, por haver uma instabilidade dos produtos medidos. É um método sensível e qualquer variação no procedimento pode afetar os resultados (Shahidi,1995). De acordo com Nawar (1985) o teor de peróxidos necessário para a percepção de ranço pode variar conforme a composição do óleo.

A estabilidade oxidativa é uma importante característica na avaliação da qualidade de óleos e gorduras, embora Shukla \& Perkins (1998) relatem que o índice de peróxido não é um bom indicador de oxidação para os ácidos polienóicos, pois uma considerável quantia de produtos secundários são formados durante os primeiros estágios da oxidação.

\subsubsection{Espectrofotometria de varredura na faixa do espectro ultravioleta}

A oxidação de ácidos graxos polinsaturados pode ser analisada pelo aumento da absortividade na faixa do espectro ultravioleta. Durante a oxidação, lipídeos contendo duplas ligações apresentam uma alteração na posição devido à ressonância na cadeia, resultando em isomerização e conjugação. A formação de dienos e trienos é proporcional ao ganho de oxigênio e à formação de peróxidos durante os estágios iniciais de oxidação. Estes dienos e trienos conjugados apresentam intensa absorção em $234 \mathrm{~nm}$ e $268 \mathrm{~nm}$, respectivamente, conforme Quadro 2. 


\begin{tabular}{|c|c|}
\hline Composto & Pico de máxima absorção (nm) \\
\hline Monoeno & 190 \\
\hline Dieno & $220-230$ \\
\hline Trieno & $265-270$ \\
\hline Tetraeno & $310-320$ \\
\hline Aldeído cetônico & $265-280$ \\
\hline \multirow[t]{2}{*}{ Aldeído cetônico $\alpha, \beta$ etilênico } & $220-250$ \\
\hline & $310-330$ \\
\hline Cetona dietilênica conjugada & $265-280$ \\
\hline$\alpha$-dicetona & 280 \\
\hline$\alpha$-cetoaldeído & 282 \\
\hline \multicolumn{2}{|l|}{ Forma enólica de $\alpha$-dicetona e } \\
\hline$\alpha$-cetoaldeído & 270 \\
\hline$\beta$-dicetona & 271 \\
\hline Ácido $\alpha$-cetônico & $210-230$ \\
\hline Ácido dietilênico conjugado & 260 \\
\hline Ácido trietilênico conjugado & 315 \\
\hline
\end{tabular}

Quadro 2. Compostos da oxidação lipídica e suas respectivas faixas de absorção no espectro do ultravioleta

Fonte: Rovellini et al. (1997)

Shahidi (1995) relatou que existe uma boa correlação entre os valores do índice de peróxido e absortividade na faixa do ultravioleta em $232 \mathrm{~nm}$ e o mesmo foi confirmado pelos resultados obtidos pela presente pesquisa e por Vieira (1998); Siqueira (1998); Almeida-Doria (1999) e Oliveira (2003). Segundo Nawar (1985), o grau de mudança na absorbância só tem boa correlação com o grau de oxidação nos primeiros estágios. A determinação da absortividade na faixa do ultravioleta em $232 \mathrm{~nm}$ têm algumas vantagens sobre o índice de 
peróxido por ser mais rápida e mais simples, e não depender de reação química ou desenvolvimento de cor (Shahidi, 1995).

\subsection{Fabricação comercial de cápsulas}

A gelatina é um produto obtido pela hidrólise parcial do colágeno, uma proteína presente na pele, do tecido conectivo branco da matriz óssea de animais. As gelatinas obtidas pelo tratamento ácido são denominadas como Tipo A e a gelatina derivada do tratamento por álcali é chamada de Tipo B. A gelatina usada para produção de cápsulas ou para tabletes pode ser colorida com uma cor certificada, e não deve conter mais que $0,15 \%$ de dióxido sulfúrico (Prista, 1992; USP 24, 2000; Banker \& Rhodes, 1996).

Efetivamente, das características da gelatina usada na fabricação depende a qualidade das cápsulas, isto é, a uniformidade da espessura da parede, a qual é dependente da viscosidade e do índice de "bloom", que expressa a rigidez do produto utilizado conforme o Quadro 3. 


\begin{tabular}{|cc|}
\hline Aplicação & Faixa de" bloom" \\
Cápsulas moles & $150-200$ \\
Cápsulas duras & $250-280$ \\
Drageamento & $160-200$ \\
\hline
\end{tabular}

Quadro 3 - Classificação do uso da gelatina quanto ao "bloom" na fabricação de cápsulas

Fonte: Stanley (1986)

É importante também que os invólucros sejam facilmente digeríveis, que não percam ou absorvam mais do que uma quantidade mínima de água, que não tenham permeabilidade à umidade e que em presença desta não modifiquem as suas propriedades mecânicas (elasticidade, dureza); que sejam, tanto quanto possível, impermeáveis ao anidrido carbônico e ao oxigênio, que não se alterem com as variações da temperatura de armazenamento e, que não permitam a exposição do interior às radiações luminosas capazes de provocar a alteração dos princípios ativos (Prista, 1992).

\subsubsection{Processo de fabricação}

Este tipo de cápsula está disponível no mercado desde o começo do século XIX. Inicialmente, o processo era lento, produzia-se uma cápsula por vez, dependia grandemente de mão-de-obra e tempo, até que em 1993 surgiu o processo contínuo desenvolvido pela R.P. Scherer. Antes disso, o processo não era bem aceito, pois as perdas para a indústria farmacêutica eram de 15 a 20\% do material e a variação de conteúdo das cápsulas de 20 a 40\%. Com esse novo processo os índices caíram para aproximadamente 3\% nos dois casos (Stanley, 1986). 
Na cápsula de gelatina mole, o invólucro é constituído basicamente por gelatina, um plastificante e água. Devido às suas características, a gelatina é a substância ideal para o encapsulamento de fármacos (Stanley, 1986).

Os produtos de gelatina estão descritos na United States Pharmacopéia (USP) com as especificações adicionais necessárias pelo fabricante dos invólucros tais como o parâmetro de resistência de "bloom", viscosidade e teor de ferro (Stanley, 1986).

A formulação do conteúdo das cápsulas para cada produto é desenvolvida individualmente para estar de acordo com os requisitos do produto. O insumo a ser encapsulado deve ser homogêneo e sem ar, devem escoar facilmente por ação da força da gravidade à temperatura ambiente, mas não a uma temperatura superior a $35^{\circ} \mathrm{C}$ durante a encapsulação, uma vez em que a temperatura em que se funde é da ordem dos 37 a $40^{\circ} \mathrm{C}$ (Stanley, 1986).

Existem coadjuvantes de formulação que aumentam a estabilidade física das cápsulas. A gelatina é pouco permeável ao oxigênio, portanto a instabilidade devido à oxidação por ação da luz é pouco freqüente, já que pode ocorrer o uso de substância opaca também (Stanley, 1986).

\subsubsection{Controle de qualidade}

As cápsulas, quando em equilíbrio com ambiente com 20 a 30\% de umidade relativa, a $21-24^{\circ} \mathrm{C}$, são consideradas secas e o invólucro dessa cápsula contém cerca de 6 a 10\% de água, dependendo da gelatina que foi usada. A umidade do invólucro é determinada pelo método de destilação com tolueno, recolhendo-se o destilado durante um período de uma hora. A água adicional pode ser removida das cápsulas secas por aquecimento (por exemplo, $\left.40^{\circ} \mathrm{C}\right)$ (Stanley, 1986). 
Os testes de qualidade utilizados para cápsulas moles incluem determinação de espessura da costura, determinação do grau de umidade do invólucro, testes de resistência à ruptura e a determinação dos efeitos de baixas e elevadas temperaturas (Stanley, 1986).

De acordo com Stanley (1986), esse tipo de cápsula necessita de um armazenamento e embalagem adequadas, já que as mesmas entram em equilíbrio com as condições atmosféricas. Não se pode esquecer que a estabilidade física das cápsulas de gelatina mole está associada, sobretudo com a absorção ou eliminação de água pelo invólucro.

\subsection{Embalagens}

Dentre as várias funções das embalagens, a de proteger está mais relacionada diretamente com a vida de prateleira do produto. E esta deverá apresentar boa barreira ao oxigênio, à umidade e às radiações luminosas, e quanto mais insaturados forem os lipídeos, maior deverá ser a proteção da embalagem (Faria, 1991).

As embalagens no setor farmacêutico têm sido cada vez mais aprimoradas, a fim de atender as necessidades técnicas e legais, e um mercado consumidor mais exigente (Lockhart \& Paine, 1996).

Lockhart \& Paine (1996) definiram que as embalagens de medicamentos devem fornecer um meio econômico de proteção, apresentação, identificação, informação e conveniência por ser um produto de origem farmacêutica. Da sua produção até a sua utilização ou administração, os medicamentos exigem um certo cuidado com relação à embalagem, pois qualquer falha que haja resultará em alterações na sua fórmula original, alterando o processo terapêutico, podendo ser prejudicial à saúde do usuário, e até levá-lo à morte.

As embalagens para produtos farmacêuticos devem apresentar características que garantam a proteção do conteúdo, permitam a sua 
identificação e a sua informação sobre a forma de utilização, a facilidade e segurança de manuseio e de fechamento (Oliveira, 1997).

Analisando-se o setor farmacêutico observa-se uma característica específica quando se compara este setor a outros setores industriais. Há uma grande diversidade de produtos e conseqüentemente de embalagens, que têm sido objeto de importantes inovações. Por isso a importância da embalagem tem se tornado cada vez mais significativa dentro deste contexto (Ortiz, 2000).

\subsubsection{Embalagens plásticas}

Entre os materiais plásticos, há consideráveis diferenças quanto às propriedades de barreira, dependente de vários fatores. A permeabilidade de um material de embalagem a uma determinada substância (permeante) é função da solubilidade e da difusibilidade do permeante no material. A solubilidade depende da diferença de polaridade entre ambos; por exemplo, polímeros com grupos polares representam boas barreiras a gases, e por outro lado, alta permeabilidade a vapor de água (Gruenwald, 1993).

O uso de materiais plásticos utilizados na fabricação de embalagem para produtos em diferentes categorias está cada vez mais comum. Para produtos farmacêuticos a utilização de materiais plásticos depende de certas aprovações (Oliveira, 1997) (Quadro 4).

De acordo com Oliveira (1997), ao contrário do vidro, os plásticos não são impermeáveis aos gases e ao vapor de água, e estas características podem variar dependendo do tipo de resina e da espessura do material. Os plásticos apresentam como características: baixo peso (menor custo de transporte e facilidade de manuseio), versatilidade em formatos, alguns plásticos têm excelentes propriedades ópticas, transparência variável (controle da incidência de luz), fechamento pela aplicação de calor, boa resistência química e não fragmentam no caso de quebra. 


\begin{tabular}{|ll|}
\hline Embalagem & Material \\
Frascos & Vidro, PEAD, PET \\
Aerosol & Alumínio \\
Bisnagas & Alumínio, PEBD, PP, estruturas \\
& plásticas com múltiplas camadas \\
Ampolas & Vidro \\
Blister & PVC, PET (fechamento com alumínio \\
& revestido) \\
Envelopes & PET/PEBD/AI/PEBD, \\
Strip & Papel/PEBD/AI/PEBD \\
Bolsas & AI/Nerniz, Al/PEBD, CELO/PEBD \\
\hline
\end{tabular}

Quadro 4 - Embalagens utilizadas para produtos farmacêuticos Fonte: Oliveira (1997)

\subsubsection{Polietileno de alta densidade}

O filme de polietileno é macio e flexível sua transparência varia, mas uma boa claridade pode ser obtida quando necessário. É inodoro e insípido, mas para algumas aplicações deve ser cuidadosamente estudado. Além disso, tem boa resistência química, exceto para óleos e gorduras. Apresenta reduzida permeabilidade à água, porém possui uma alta taxa de transferência de gases para alguns produtos, colocando-o em desvantagem em relação a outros tipos de filmes (Hanlon, 1971). 


\subsubsection{Vidro}

As embalagens de vidro são de ampla aceitação no mercado já que aliam transparência, boa conservação, são inertes física e quimicamente, e desde que bem fechadas não permitem contato com o oxigênio e umidade. Suportam altas temperaturas, são resistentes e podem ser recicladas continuamente sem perder suas características, colaborando com menor impacto ambiental (Ortiz et al., 2000).

Um vez que os vidros são totalmente impermeáveis a qualquer tipo de substância, é um material ideal para embalagem, porém, dado seu alto custo e por ser constituído de material que confere um maior peso na embalagem final o seu uso é limitado (Gruenwald, 1993).

As embalagens de vidro também seriam mais eficientes do ponto de vista da proteção do óleo contra a oxidação, já que têm a vantagem, em relação aos materiais plásticos, de minimizar o acesso do oxigênio (Tawfik \& Huyghebaert, 1999).

\subsection{3 "Blisters"}

$\mathrm{Na}$ indústria farmacêutica as embalagens preferidas são frascos ou blisters, sendo que os filmes mais comumente utilizados para o blister são policloreto de vinila (PVC), cloreto de polivinilideno (PVDC) policlorotrifluoroetileno (PCTFE) de nome comercial ACLAR (Allen, 1999).

A embalagem "blister" passou a ser aceita em meados dos anos 60, quando foi formulada a pílula anticoncepcional, por ser a maneira mais apropriada para orientar a administração deste medicamento, oferecendo aos usuários uma dose individual diária com segurança (Pilchik, 2000).

De acordo com Pilchik ( 2000), além de oferecer segurança na forma de dosagem individual, o "blister" também oferece maior proteção contra agentes externos que as embalagens convencionais, reduzindo a chance de 
contaminação do produto. As vantagens oferecidas por esse tipo de embalagem são muitas, dentre elas destaca-se a ausência de frascos de vidros quebrados, redução de custos e maior rapidez no processo de embalagem, assim como a dificuldade de adulteração da embalagem. Nas embalagens de "blisters" cada dose pode ser identificada pelo nome do produto, número de lote e data da validade do produto, além de assegurar a integridade do produto e o fabricante desde a sua fabricação e distribuição até o consumidor.

\subsubsection{Principais componentes para formação do "blister"}

O "blister" é composto pelo filme moldador, material de cobertura e a cobertura, na qual se faz a selagem a quente e impressão à tinta. O filme moldador e o material de cobertura formam uma embalagem integrada, devendo se encaixar adequadamente. O filme formador é o componente da embalagem que recebe o produto em forma de bolsa como pode ser visto na Figura 5 que demonstra o processo de fabricação do "blister". 


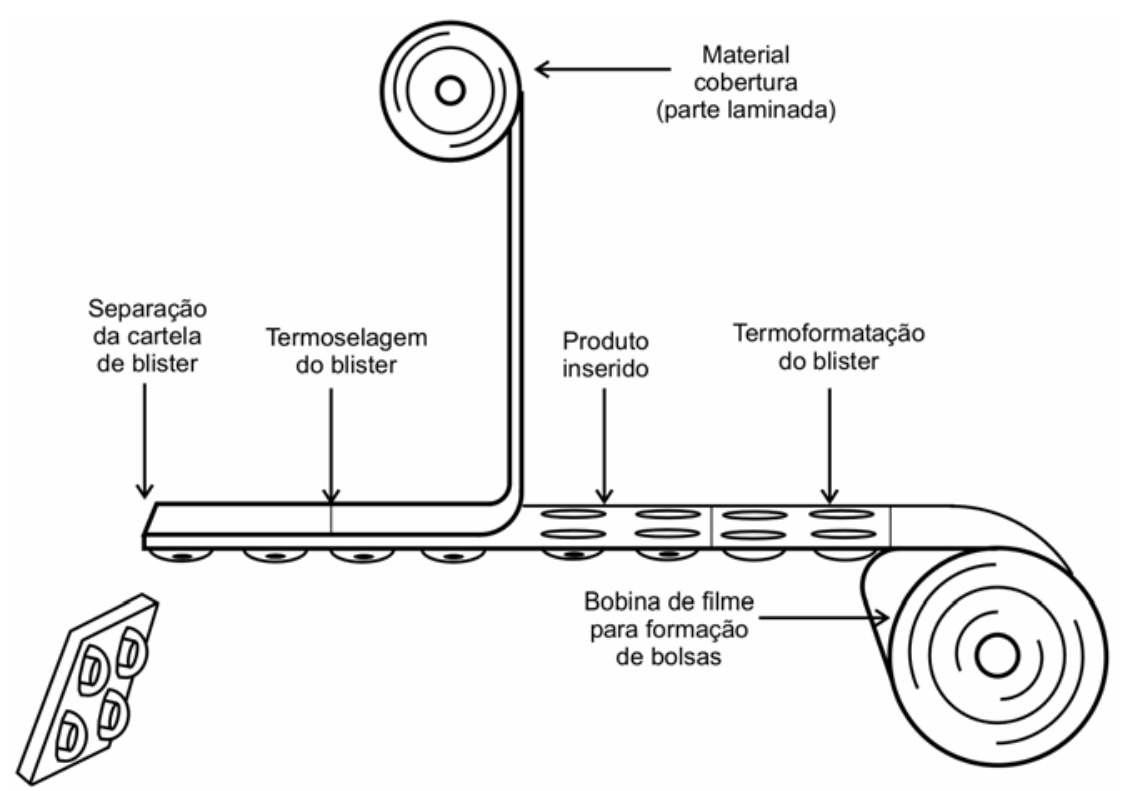

Figura 5 - Processo de fabricação do "blister"

Fonte: Pilchik (2000)

A escolha do filme deve considerar a resistência a impactos, o transporte e o custo do filme. Este deve ser compatível com o produto, mas algumas características devem ser levadas em consideração tais como: produção e velocidade da montagem, incluindo as propriedades de selagem a quente e a facilidade de separar os "blisters" formados (Pilchik, 2000).

Os filmes formadores geralmente são incolores e transparentes, mas podem ser escurecidos para embalagens de uso infantil ou para proteger as drogas sensíveis à luz. São quase sempre de PVC, que pode ser coberto ou laminado com componentes adicionais que aumentam a barreira ao vapor de água e ao oxigênio (Pilchik, 2000). Os diferentes tipos de filmes utilizados para a formação de "blisters" estão classificados conforme sua adaptação às 
diferentes zonas climáticas pela Comunidade Européia ${ }^{1}$ que estão relacionadas nas Figura 6 e Quadro 5

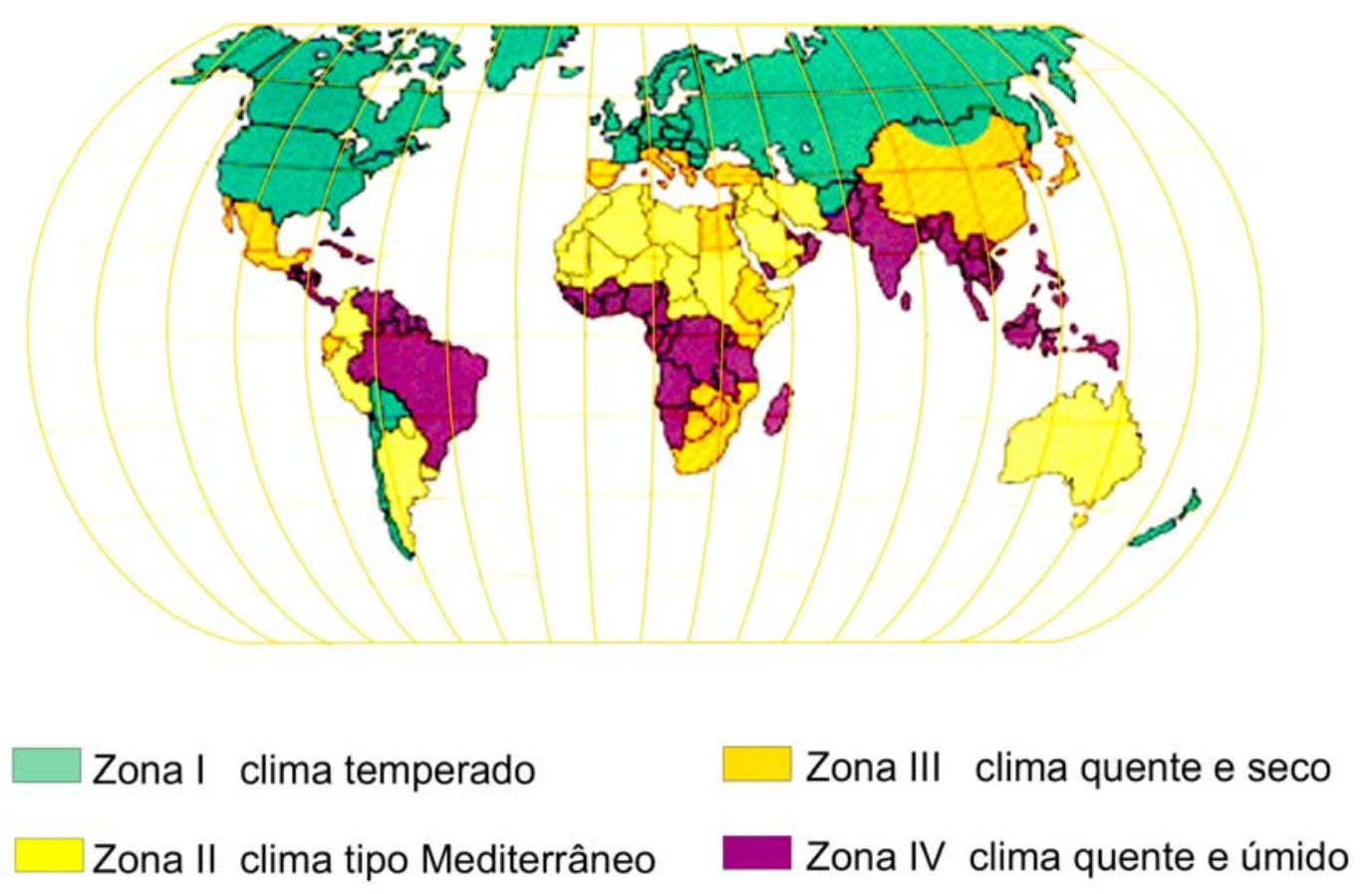

Figura 6 - Diferentes zonas climáticas na Comunidade Européia

\footnotetext{
${ }^{1}$ Cardinal Health Brasil. Zones Climatiques (règles concernant lês produits pharmaceutiques dans la Communauté Européenne Vol. III, page 30, 1989).
} 


\begin{tabular}{|c|c|c|c|}
\hline Material & $\begin{array}{l}\text { Proteção } \\
\text { Relativa à Umidade } \\
\text { antes da } \\
\text { encapsulação }\end{array}$ & $\begin{array}{l}\text { Zonas } \\
\text { climáticas }\end{array}$ & Comentários \\
\hline PVC & 1 & nenhuma & $\begin{array}{l}\text { Pouco recomendada para } \\
\text { acondicionar cápsulas moles. }\end{array}$ \\
\hline Polipropileno & 2 a 3 & I, II & $\begin{array}{l}\text { Resistência boa à umidade, mas } \\
\text { permeável a gás. } \\
\text { Dificuldade para controlar a } \\
\text { termoformação em razão de } \\
\text { temperaturas elevadas. }\end{array}$ \\
\hline $\begin{array}{l}\text { PVC } 250 / \\
\text { PVDC } 60 \mathrm{~g} / \mathrm{m}^{2}\end{array}$ & 3 a 5 & I, II & $\begin{array}{l}\text { Geralmente recomendada para } \\
\text { blisters na Europa. }\end{array}$ \\
\hline $\begin{array}{l}\text { Polipropileno/ } \\
\text { PVDC }\end{array}$ & 3 a 5 & I, II & $\begin{array}{l}\text { Impermeabilidade superior ao } \\
\text { polipropileno simples. } \\
\text { Dificuldade para a termoformação. } \\
\text { Este material deveria tomar um lugar } \\
\text { bem mais importante na técnica de } \\
\text { "blisters". }\end{array}$ \\
\hline $\begin{array}{l}\text { PVC/PE/PVDC } \\
\text { ("Triplex") }\end{array}$ & 2 a 10 & I, II, III, IV & $\begin{array}{l}\text { Excelente proteção com os filmes } \\
\text { Triplex espessos. }\end{array}$ \\
\hline Aclar/PVC & 10 a 12 & I,II,III,IV & $\begin{array}{l}\text { Materiais muito eficazes com ótima } \\
\text { proteção para todos os climas. Os } \\
\text { filmes em Triplex ou Aclar podem ser } \\
\text { úteis em zonas climáticas I e II para } \\
\text { certas preparações contendo } \\
\text { materiais higroscópicos. }\end{array}$ \\
\hline
\end{tabular}

Quadro 5 - Materiais para a formação dos "blisters" e sua adequação conforme as zonas climáticas

Fonte: Cardinal Health Brasil 


\subsubsection{Policloreto de vinila}

O filme formador policloreto de vinila também chamado de PVC rígido ou vinil, foi introduzido comercialmente em 1927, sendo empregado nas mais diversas formas. É um polímero termoplástico, tendo como estrutura química $\left(-\mathrm{CH}_{2} \mathrm{CHCL}-\right)_{\mathrm{n}}$ (Hanlon, 1971).

É chamado de PVC rígido porque ele é praticamente isento de agentes amolecedores. É um material muito claro e duro com baixa capacidade de transmissão de vapor de água, apresenta excelente termomoldabilidade e uma alta força de flexibilidade. Estas propriedades fazem do PVC rígido o material de escolha para embalagens de blisters. Os filmes de PVC que são termomoldáveis têm uma espessura de aproximadamente $10 \mu$ (Pilchik, 2000).

O PVC está entre os filmes de mais baixo custo e é o mais freqüentemente usado para embalagens de drogas. Ele possui boas propriedades de barreira a óleos e gorduras. O PVC é termossensível, decompondo-se acima de $80^{\circ} \mathrm{C}$. Quando exposto à luz do sol tem um efeito degradante, causando amarelecimento do plástico. As características do filme de cloreto de polivinila estão relacionadas com os aditivos que são usados. Estão incluídos os plastificantes, antioxidantes e os antiestáticos. Pascal et al. (1995) relataram que para reduzir a transmissão de luz de materiais plásticos existem os absorvedores de luz ultravioleta. De acordo com Gugumus (1990), o mecanismo de ação dos absorvedores baseia-se na absorção da radiação ultravioleta e dissipação da energia de uma forma que não resulte em fotossensibilização. Os melhores plastificadores são altamente tóxicos e não são recomendados para uso com produtos alimentícios (Hanlon, 1971). O PVC é freqüentemente preferido para produtos farmacêuticos pelo seu baixo custo e pela facilidade no processamento. Apresenta, porém, uma desvantagem, a sua propriedade de barreira à umidade é mínima (Hunt, 1999). 


\subsubsection{Cloreto de polivinilideno}

O cloreto de polivinilideno, PVDC, é um termoplástico, baseado no homopolímero 1,1-dicloroetileno. É um monômero com um átomo de cloro a mais do que o monômero de cloreto de vinila. Este homopolímero é difícil de ser processado e resulta em um filme muito rígido, e de pouca utilidade para embalagem, portanto ele é copolimerizado com cloreto de vinila, acrilato ou nitrila, isto é, dependendo das finalidades às quais for destinado. O PVDC tem sido usado como material de embalagem desde meados de 1946. Dentre todos os filmes, ele é um dos que tem melhores propriedades de barreira como controlador de umidade e gases (aromas), possuindo também alta resistência química. Preserva sabores e odores, tem boa resistência a óleos e gorduras em temperatura ambiente, mas quando exposto a temperaturas elevadas esta resistência cai; é um filme relativamente caro para embalagens (Hanlon, 1971). Em aplicações de revestimentos, o PVDC pode ser utilizado para combinar barreira com termosselabilidade a si mesmo ou a outros substratos (Sarantópoulos et al., 2002). Embora o volume de PVDC na embalagem seja pequeno, ele tem uma função importante nos "blisters" como laminações ou coberturas de PVC (Pilchik, 2000).

\subsubsection{Policlorotrifluoretileno}

É um co-polímero e comercializado sob o nome de ACLAR. É um filme transparente que atua bem em temperaturas muito altas ou baixas, tem propriedades de barreiras excepcionais e é altamente resistente a agentes químicos corrosivos. Como seu custo é um tanto elevado, o seu uso em embalagens é limitado (Hanlon, 1971). É empregado em processos de laminação e não de revestimento. Nos primeiros, é combinado com PVC ou PVC/PE (polietileno) para reduzir custos (Hunt, 1999). 


\section{MATERIAIS E MÉTODOS}

\section{1 Óleo de peixe encapsulado}

O óleo utilizado nesse experimento foi cedido pela indústria farmacêutica RP Scherer Brasil, já refinado e encapsulado, em cápsulas de gelatina moles, tamanho 10, oval, sem adição de vitamina $\mathrm{E}$ como antioxidante, num total de 15 mil unidades (Figura 7).

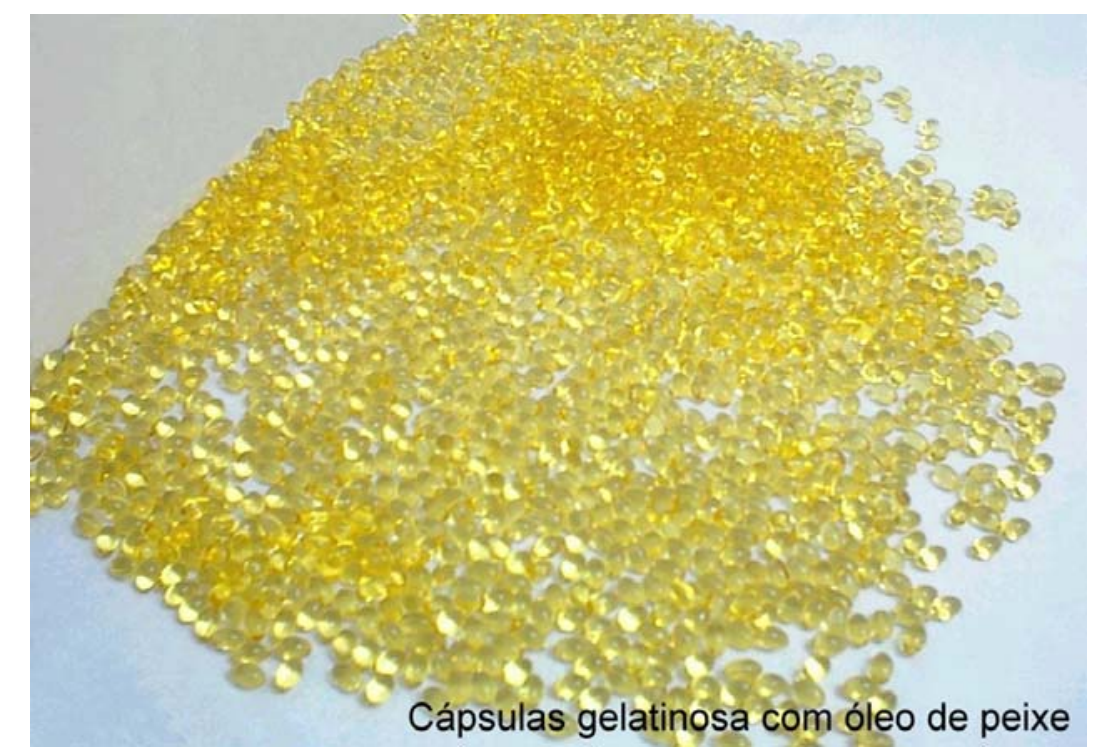

Figura 7 - Cápsulas gelatinosas de óleo de peixe

Após a encapsulação, parte das amostras ( 7.500 mil cápsulas) foi enviada à Empresa SERPAC Comércio e Indústria Ltda para o processo de 
emblistagem com filme policlorotrifluoroetileno (PCTFE), comercializado sob o nome Aclar Rx $160(15 \mu)$, cloreto de polivinilideno (PVDC -60gsm) e policloreto

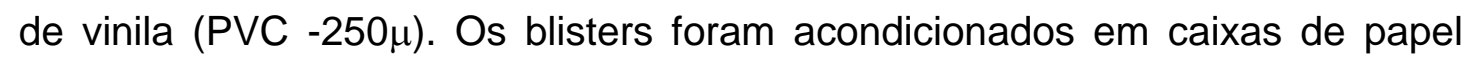
cartonado de forma a conter 60 cápsulas por caixa. A outra parte $(7.500 \mathrm{mil}$ cápsulas) foi acondicionada em frascos de polietileno de alta densidade (PEAD) com e sem sachês de sílica e em vidro de cor âmbar, também contendo 60 cápsulas em cada frasco (Figura 8).

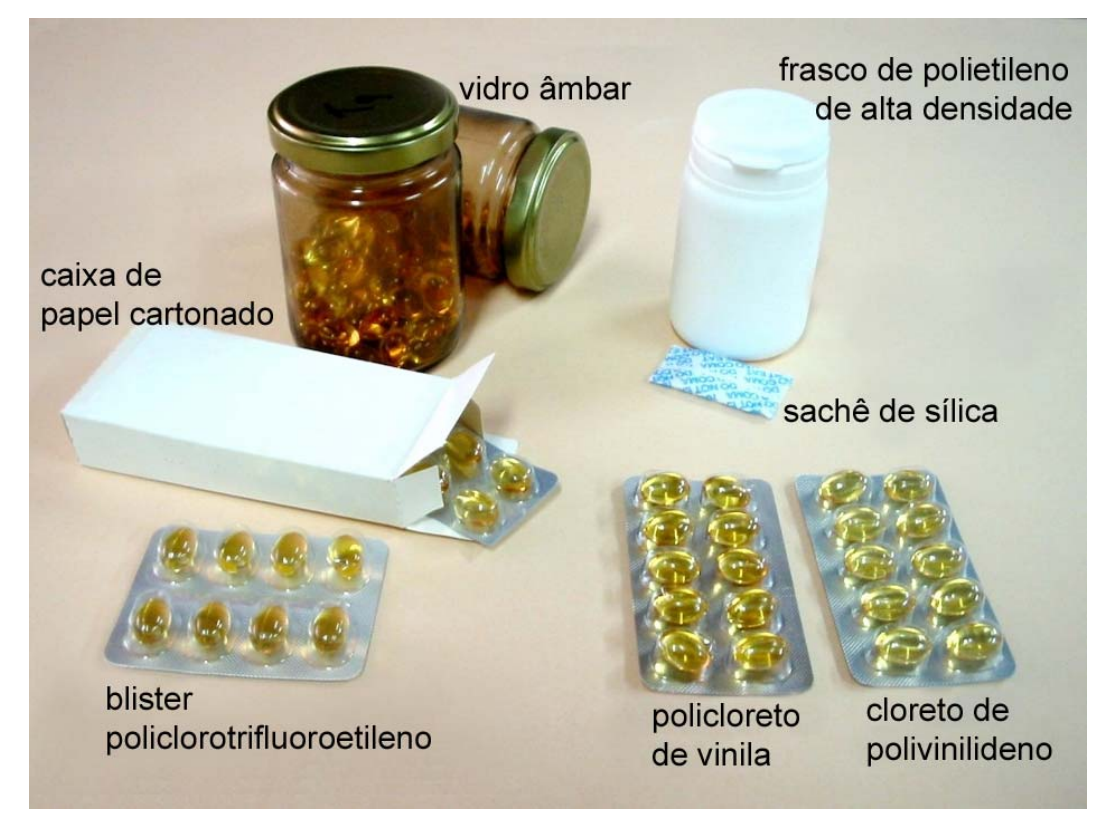

Figura 8 - Embalagens utilizadas no experimento 


\subsection{Métodos}

\subsubsection{Análises químicas}

\subsubsection{1 Ácidos graxos livres}

Foi determinado segundo as normas da AOCS Cd 5-40 (1997), através da dissolução de amostras de $5 \mathrm{~g}$ de óleo em álcool etílico a quente $\left(60-65{ }^{\circ} \mathrm{C}\right)$ e titulação com hidróxido de sódio 0,1 N. O volume gasto refletiu a porcentagem de ácidos graxos livres (expresso em ácido oléico) através da fórmula (1):

$\% A G L=(m L$ de hidróxido de sódio $\times 28,2 \times N)$

$\mathrm{m}$

Sendo: $\mathrm{N}=$ normalidade da solução de hidróxido de sódio $\mathrm{m}=$ massa da amostra em $(\mathrm{g})$

\subsubsection{2 Índice de peróxido}

Segundo as normas da AOCS Cd 8b-90 (1997), o índice de peróxido foi determinado através da dissolução de amostras de $5 \mathrm{~g}$ de óleo em solução de ácido acético glacial e isooctano (3:2, v/v) e adição de solução de iodeto de potássio saturada, seguida de titulação com solução de tiossulfato de sódio 0,01 N. O volume gasto após a adição da goma de amido indicou a concentração de peróxidos em meq $\mathrm{O}_{2} / \mathrm{kg}$, através da fórmula (2): 
$I P=[\underline{N \times(A-B) \times 1000}]$

$\mathrm{m}$

Sendo: $A=m L$ de tiossulfato de sódio gastos com a titulação da amostra

$B=m L$ de tiossulfato gastos com a titulação dos reagentes sem a amostra

$\mathrm{N}=$ normalidade da solução de tiossulfato de sódio

$\mathrm{m}=$ massa da amostra $(\mathrm{g})$

\subsubsection{Análises físicas}

\subsubsection{Absortividade em 232 e $270 \mathrm{~nm}$}

De acordo com a NDG C-40 (SSOG, 1976), a amostra de óleo foi diluída em isoctano, para a leitura da absorbância estivesse entre 0,2 e 0,8. Foram utilizados balões de 25 ou $50 \mathrm{~mL}$ de capacidade, dependendo do estado oxidativo do óleo. O espectrofotômetro utilizado foi Shimadzu, modelo UV 1203, sendo os resultados expressos em absortividade pela fórmula (3):

$E_{n m}=A /(c . d)$

Sendo: $E$ = extinção específica ou absortividade no comprimento de onda (nm) $A=$ absorbância registrada no comprimento de onda utilizado $c=$ concentração $(\mathrm{g} / 100 \mathrm{~mL})$ da solução da amostra $\mathrm{d}=$ largura da cubeta utilizada $(\mathrm{cm})$ 


\subsubsection{Espectro de absortividade na faixa do espectro ultravioleta - 220 a} $320 \mathrm{~nm}$

Esta análise foi conduzida de acordo com IUPAC (1979), método 2.505, com as mesmas diluições em isoctano usadas na determinação anterior (3.2.2.1) no mesmo equipamento. Foi utilizado o programa "Personal Spectroscopy" versão 1.1, e cada valor de absorbância foi convertido em absortividade através do fator de concentração, como no item anterior.

\subsubsection{Cromatografia gasosa}

Os ésteres metílicos do óleo foram preparados de acordo com Hartman \& Lago (1973).

A análise da composição em ácidos graxos EPA e DHA foi realizada em cromatógrafo marca Agilent, modelo 6890 N, dotada de coluna Innowax de $30 \mathrm{~m} \times 2,5 \mathrm{~mm} \times 0,25 \mathrm{~mm}$ de espessura de filme; com fluxo de gases: $\mathrm{H}_{2}, 2 \mu \mathrm{L}$ /minuto; ar, $350 \mathrm{~mL} /$ minuto e $\mathrm{N}_{2}, 30 \mathrm{~mL} /$ minuto; temperatura da coluna, $195^{\circ} \mathrm{C}$; do injetor, $270^{\circ} \mathrm{C}$, e do detector, $270^{\circ} \mathrm{C}$; com a seguinte programação: tempo inicial de 15 minutos à razão de $1^{\circ} \mathrm{C} /$ minuto, atingindo a temperatura final de $215^{\circ} \mathrm{C}$ após 40 minutos. O volume injetado foi de $2 \mu \mathrm{L}$.

\subsection{Experimento}

\subsubsection{Armazenamento ao ambiente}

As 7.500 cápsulas de óleo de peixe emblistadas acondicionados em filmes de PCTFE, PVDC e PVC acondicionadas em embalagens de caixas de papel cartonado juntamente com as outras 7.500 cápsulas acondicionadas em frascos de polietileno de alta densidade com e sem sachê de sílica e frascos de vidro âmbar foram armazenadas em condições ambiente, no Laboratório de 
Óleos e Gorduras do Departamento de Agroindústria, Alimentos e Nutrição (ESALQ/USP), por doze meses. No momento das análises, o óleo das cápsulas foi retirado das mesmas com ajuda de uma seringa. As análises de absortividade em 232 e $270 \mathrm{~nm}$, acidez e índice de peróxido foram realizadas a cada vinte e oito dias. A quantificação dos ácidos graxos EPA e DHA foi realizada no primeiro, terceiro, sexto e décimo segundo mês. Cada tratamento (embalagem: material (filme dos blisters e frascos) foi avaliado em triplicata durante o armazenamento de 12 meses sob condições ambientes. A Tabela 1 apresenta as condições de temperatura e umidade relativa prevalentes durante o período experimental. O ambiente foi mantido sob condições de iluminação norma.

\subsubsection{Análise estatística}

Os ensaios foram conduzidos no esquema fatorial, modelo inteiramente ao acaso, considerando os fatores tipo embalagens em 6 níveis, e período de armazenamento em 12 níveis. A variabilidade dos dados foi analisada através da Anova, com teste F. A comparação dos efeitos médios foi analisada através do Teste de Tukey, considerando o nível de significância de 5\%. Os dados foram processados através do Statistical Analysis System SAS (1996). 


\section{RESULTADOS E DISCUSSÃO}

As cápsulas embaladas foram mantidas no laboratório sob condições de 700 Lumem de iluminação durante 8 a 10 horas diárias e temperaturas e umidades relativas, apresentadas na Tabela 1, anotadas no dia da amostragem para análise.

Tabela 1. Temperatura e umidade relativa ambiente do local do armazenamento das cápsulas durante o período experimental

\begin{tabular}{cccc}
\hline PERÍODO & MÊS & TEMPERATURA $\left({ }^{\circ} \mathrm{C}\right)$ & $\begin{array}{c}\text { UMIDADE }(\%) \\
\text { RELATIVA }\end{array}$ \\
\hline Início & Julho & 24,3 & 67 \\
1 & Agosto & 25,2 & 66 \\
2 & Setembro & 24,3 & 59 \\
3 & Outubro & 23,5 & 67 \\
4 & Novembro & 30 & 64 \\
5 & Dezembro & 29 & 58 \\
6 & Janeiro & 30 & 58 \\
7 & Fevereiro & 28,4 & 90 \\
8 & Março & 28,6 & 92 \\
9 & Abril & 28,2 & 70 \\
10 & Maio & 24 & 80 \\
11 & Junho & 18 & 80 \\
12 & Julho & 16 & 96 \\
\hline
\end{tabular}


Analisados os óleos quanto à sua qualidade, os resultados da acidez variaram de 0,15 a 0,33\% de ácido oléico entre os tratamentos e períodos de armazenamento, indicando que as condições experimentais (ambiente e embalagem) não foram favoráveis à ocorrência da hidrólise dos triglicerídeos. A Figura 9 apresenta as curvas de variação da acidez do óleo em função do tempo. As embalagens provocaram comportamentos semelhantes, destacandose a de PVDC que apresentou maiores oscilações, sem, contudo se diferenciar estatisticamente.

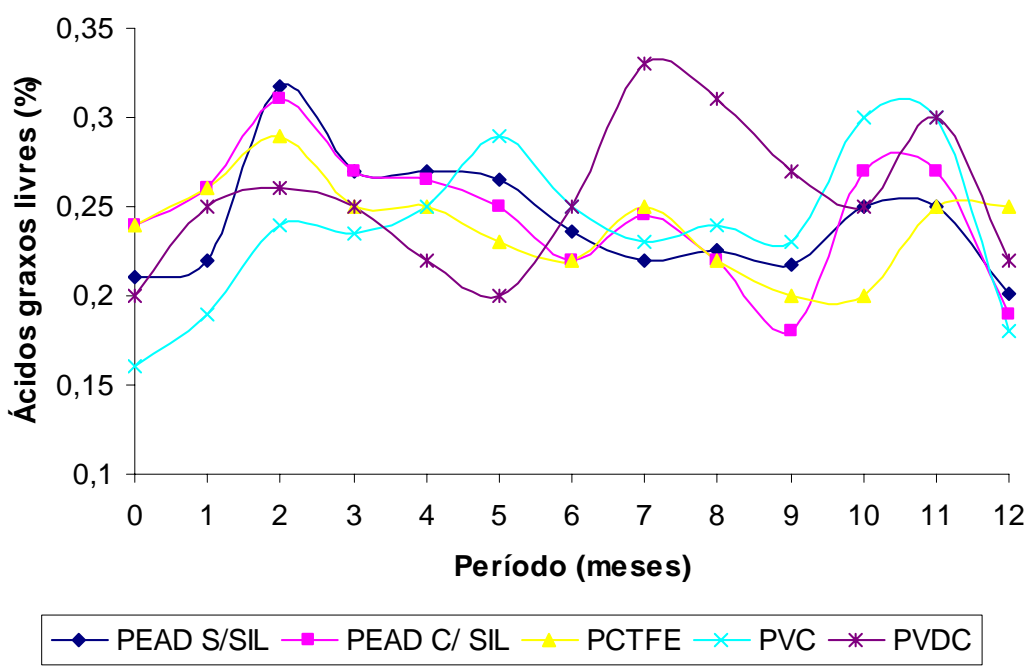

PEAD S/Sil = frasco de polietileno de alta densidade sem sachê de sílica PEAD C/Sil = frasco de polietileno de alta densidade com sachê de sílica VIDRO

PCTFE= "blister" com filme policlorotrifluoretileno

PVC = "blister" com filme policloreto de vinila

PVDC = "blister" com filme cloreto de polivinilideno

Figura 9 - Acidez (\% ácido oléico) do óleo de peixe encapsulado e acondicionado em diferentes tipos de embalagem por 12 meses. 
Se a estabilidade hidrolítica do óleo de peixe foi mantida durante o armazenamento, o mesmo não se pode dizer acerca do seu comportamento oxidativo, que se diferenciou em função da proteção que a embalagem ofereceu. Nas Tabela 2 e Figura 10 (com inclusão dos desvios mínimos significativos, DMS), observa-se a influência do tipo de embalagem sobre o índice de peróxido dos óleos encapsulados. Pode-se observar que, ao longo do período de armazenagem, a embalagem que menos protegeu o óleo foi o "blister" com filme de policloreto de vinila (PVC), que se destaca pelos mais altos valores encontrados a partir do $6^{\circ}$ mês até o final do experimento, diferenciando-se estatisticamente dos demais tratamentos. Tanto os "blisters" de policlorotrifluoretileno (PCTFE) quanto os de cloreto de polivinilideno (PVDC) apresentaram proteção semelhante e maior que os de PVC ao óleo, contudo inferior às embalagens rígidas.

Em geral, os filmes dos "blisters" quando adicionada uma camada de PVDC apresentam uma boa proteção contra o vapor de água e ao oxigênio. Como a maioria dos fármacos é hidrossolúvel, a preocupação da indústria farmacêutica está voltada para impedir a entrada da água dentro da cápsula.

Quando do planejamento deste experimento, a recomendação de uso do filme PCTFE, mais caro do que a maioria trazia embutida uma expectativa de melhor desempenho, dadas as suas propriedades de barreira. A permeabilidade que este filme e o PVDC apresentam ao oxigênio e a umidade é grande. Geralmente o PCTFE não é utilizado sozinho por ter seu custo elevado (Allinson et al., 2001). Quanto ao PVC, tem um baixo custo mas não proporciona boas barreiras de proteção, comumente usado pela industria farmacêutica. Conforme Korab (1999) citado por Allinson (2001), a taxa de transmissão do vapor de água para o filme PVC $250 \mu$ adicionado de PCTFE 9 $\mu$ é 15 vezes mais alta do que a do PVC $250 \mu$, quando utilizado sozinho. Apesar do "blister" de PVC serem bastante utilizados, ele não é recomendado para produtos sensíveis à ação do oxigênio e à umidade (Substituição dos 
filmes, 1998). Em um estudo feito por Amidon \& Middleton (1988) com a permeabilidade dos "blisters" de PVC e com PVDC laminado com PCTFE para a umidade de fármacos, obtiveram-se os seguintes resultados: para o blister de PVC, a difusão do vapor de água foi de aproximadamente 1,06 mg através de $5.8 \mathrm{~cm}^{2}$ da embalagem por dia e para o filme de PVC laminado de PCTFE foi aproximadamente de $0,11 \mathrm{mg}$ por dia por $5.8 \mathrm{~cm}^{2}$.

Em geral, dentre as embalagens rígidas, o óleo encapsulado acondicionado nos frascos de vidro apresentou grandes oscilações no índice de peróxido, ao longo dos meses de experimento, mantendo, apesar de tudo, valores menores do que nos óleos contidos nos "blisters". As embalagens que mais protegeram o óleo de peixe encapsulado da oxidação foram os frascos de polietileno de alta densidade com e sem sachê de sílica. Depreende-se que as embalagens rígidas foram mais eficientes no impedir a troca de gases com o ambiente, reduzindo a exposição do óleo ao oxigênio.

Os valores iniciais de peróxido foram todos reduzidos com a proteção que as embalagens ofereceram. Entende-se que entre a encapsulação e a embalagem final pode ter ocorrido relativa oxidação, que foi freada com as condições experimentais. Os peróxidos, sendo componentes instáveis, se quebraram e isso deve explicar a redução dos valores após 28 dias de armazenamento. Interessante também é ressaltar, que nenhuma das embalagens rígidas favoreceu a oxidação em razão suficiente para voltar a atingir os valores iniciais. 
Tabela 2. Índice de peróxido (meq $\mathrm{O}_{2} / \mathrm{kg}$ de óleo) do óleo de peixe encapsulado e acondicionado em diferentes tipos de embalagem por 12 meses.

\section{TEMPO}

\begin{tabular}{cllllll}
\hline MÊS & PEAD SISIL PEAD CISIL VIDRO & PCTFE & PVC & PVDC \\
0 & $3,66^{\mathrm{abA}}$ & $3,71^{\mathrm{abA}}$ & $3,70^{\mathrm{abA}}$ & $2,92^{\mathrm{CA}}$ & $3,73^{\mathrm{aCD}}$ & $3,60^{\mathrm{bA}}$ \\
1 & $2,22^{\mathrm{bBC}}$ & $2,58^{\mathrm{aB}}$ & $1,95^{\mathrm{bcABC}}$ & $1,37^{\mathrm{dCD}}$ & $1,53^{\mathrm{dD}}$ & $1,66^{\mathrm{cdB}}$ \\
2 & $1,10^{\mathrm{bE}}$ & $1,66^{\mathrm{abDE}}$ & $1,85^{\mathrm{aABC}}$ & $1,47^{\mathrm{abCD}}$ & $1,70^{\mathrm{aD}}$ & $1,50^{\mathrm{abB}}$ \\
3 & $1,79^{\mathrm{bBCDE}}$ & $1,43^{\mathrm{bDE}}$ & $1,49^{\mathrm{bBC}}$ & $1,52^{\mathrm{bCD}}$ & $2,33^{\mathrm{aCD}}$ & $1,79^{\mathrm{bB}}$ \\
4 & $2,24^{\mathrm{abCBC}}$ & $2,27^{\mathrm{abBC}}$ & $2,77^{\mathrm{aAB}}$ & $1,69^{\mathrm{cBCD}}$ & $2,70^{\mathrm{aCD}}$ & $2,01^{\mathrm{bcB}}$ \\
5 & $1,91^{\mathrm{bcBC}}$ & $2,27^{\mathrm{bBC}}$ & $1,64^{\mathrm{cBC}}$ & $1,95^{\mathrm{cbB}}$ & $3,28^{\mathrm{aCD}}$ & $2,13^{\mathrm{bcB}}$ \\
6 & $1,95^{\mathrm{bBC}}$ & $1,78^{\mathrm{bBCD}}$ & $1,89^{\mathrm{bABC}}$ & $1,56^{\mathrm{bBCD}}$ & $5,33^{\mathrm{aBC}}$ & $2,01^{\mathrm{bB}}$ \\
7 & $1,72^{\mathrm{bCDEF}}$ & $1,42^{\mathrm{bDE}}$ & $1,69^{\mathrm{bBC}}$ & $1,66^{\mathrm{bBCD}}$ & $4,35^{\mathrm{aC}}$ & $1,88^{\mathrm{bB}}$ \\
8 & $1,36^{\mathrm{bF}}$ & $1,20^{\mathrm{bE}}$ & $2,02^{\mathrm{bABC}}$ & $1,83^{\mathrm{bBCD}}$ & $5,04^{\mathrm{aBC}}$ & $1,92^{\mathrm{bB}}$ \\
9 & $1,47^{\mathrm{cE}}$ & $1,47^{\mathrm{CDE}}$ & $3,13^{\mathrm{bA}}$ & $1,63^{\mathrm{bBCD}}$ & $5,92^{\mathrm{aABC}}$ & $2,11^{\mathrm{bcB}}$ \\
10 & $1,56^{\mathrm{bCD}}$ & $1,33^{\mathrm{bDE}}$ & $1,40^{\mathrm{bC}}$ & $2,71^{\mathrm{bA}}$ & $6,79^{\mathrm{aAB}}$ & $3,00^{\mathrm{bA}}$ \\
11 & $1,63^{\mathrm{cdCDEF}}$ & $1,34^{\mathrm{dD}}$ & $2,67^{\mathrm{bcABC}}$ & $2,97^{\mathrm{bA}}$ & $7,50^{\mathrm{aA}}$ & $2,87^{\mathrm{bA}}$ \\
12 & $1,70^{\mathrm{cCDEF}}$ & $1,50^{\mathrm{cCD}}$ & $2,13^{\mathrm{cABC}}$ & $3,07^{\mathrm{bA}}$ & $6,56^{\mathrm{aAB}}$ & $2,89^{\mathrm{bA}}$ \\
\hline
\end{tabular}

Nota: Os resultados constituem médias de três repetições; as médias seguidas por letras minúsculas na horizontal oferecem a comparação dentro do período entre os tratamentos; e, por letras maiúsculas, a comparação dentro do tratamento entre os períodos de armazenamento. 


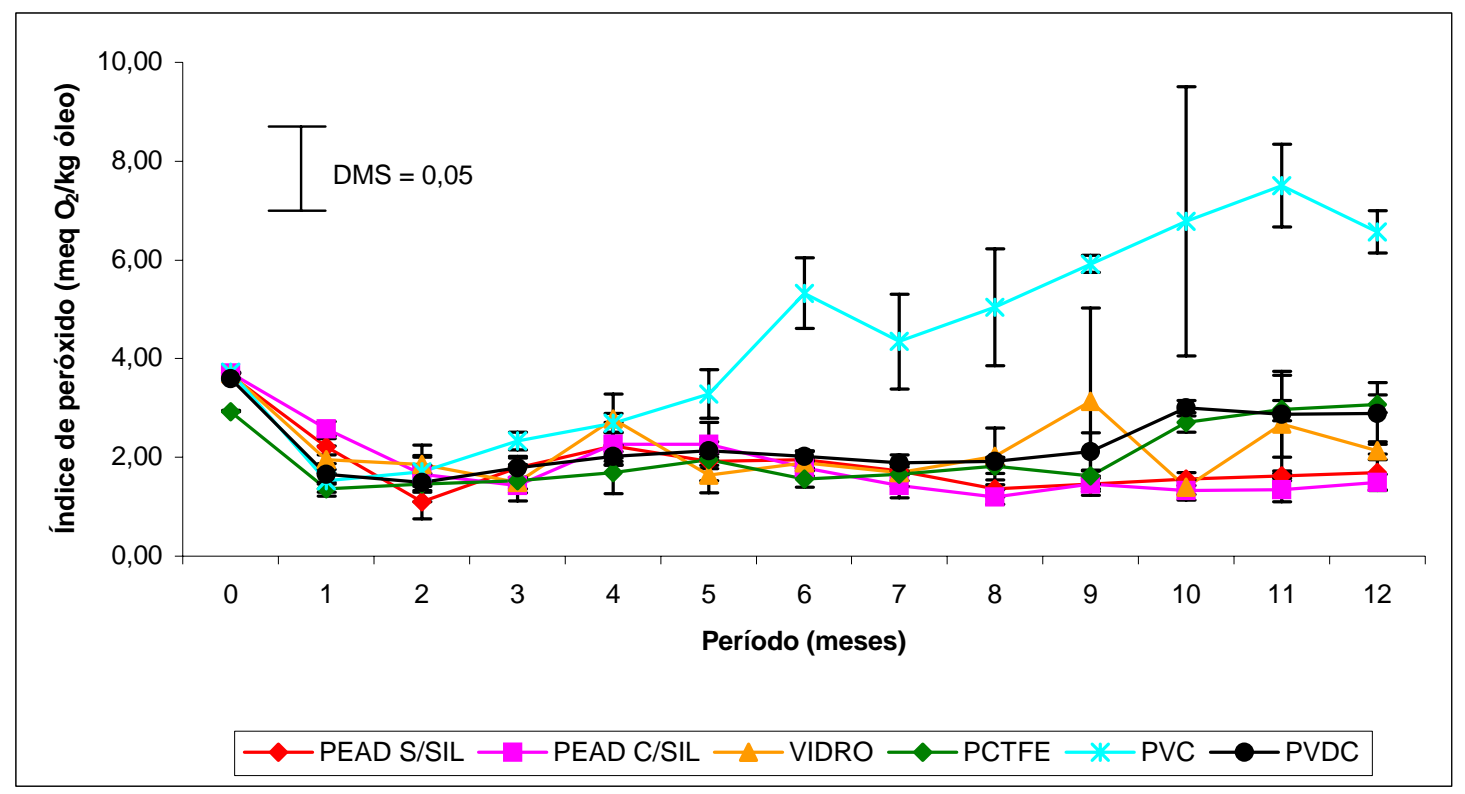

Figura 10 - Índice de peróxido (meq $\mathrm{O}_{2} / \mathrm{kg}$ de óleo) do óleo de peixe encapsulado e acondicionado em diferentes tipos de embalagem por 12 meses. Cada ponto representa \pm um desvio padrão da média de três repetições

CV (coeficiente de variação) $=22,53 \%$

PEAD S/Sil = frasco de polietileno de alta densidade sem sachê de sílica

PEAD C/Sil = frasco de polietileno de alta densidade com sachê de sílica VIDRO

PCTFE= "blister" com filme policlorotrifluoretileno

$\mathrm{PVC}=$ "blister" com filme policloreto de vinila

PVDC = "blister" com filme cloreto de polivinilideno

Apesar de não haver uma regulamentação do Ministério da Saúde para o índice de peróxido para o óleo de peixe encapsulado e destinado como suplemento alimentar, se forem obedecidas as normas para os óleos vegetais 
comestíveis, os valores encontrados no presente estudo apresentam-se dentro do limite da legislação do Ministério da Saúde do Brasil, resolução $n^{\circ} 482$, anexo 4 (2001) (10 meq/kg peróxido). Porém, Mounts (1994), relatou que, desde o ano de 1993, o Codex Alimentarius estabeleceu $5 \mathrm{meq} / \mathrm{kg}$, como máximo, para qualquer óleo refinado. Se esta fosse a situação vigente no Brasil, o óleo de peixe acondicionado na embalagem de "blister" de PVC teria o seu prazo de validade máximo inferior a 12 meses, mais precisamente, 7 meses, como mostra a Tabela 2.

Os valores de absortividade na faixa do ultravioleta do espectro espelham o estado oxidativo do óleo, visto identificarem o acúmulo de compostos primários e secundários resultantes da oxidação.

A Tabela 3 e Figura 11 apresentam os valores de absortividade em 232 $\mathrm{nm}$ dos óleos de peixe encapsulados para todas as embalagens. 
Tabela 3. Absortividade em $232 \mathrm{~nm}$ do óleo de peixe encapsulado e acondicionado em diferentes tipos de embalagem por 12 meses

\begin{tabular}{cllllll}
\hline TEMPO & & \multicolumn{5}{c}{ TRATAMENTOS } \\
\hline MÊS & PEAD SISIL & PEAD C/SIL & VIDRO & PCTFE & PVC & PVDC \\
0 & $9,32^{\mathrm{aA}}$ & $8,22^{\mathrm{bCAB}}$ & $8,20^{\mathrm{bCAB}}$ & $8,97^{\mathrm{bCABC}}$ & $8,21^{\mathrm{bcDE}}$ & $7,89^{\mathrm{cB}}$ \\
1 & $8,28^{\mathrm{abB}}$ & $7,84^{\mathrm{abCB}}$ & $8,0^{\mathrm{abAB}}$ & $8,32^{\mathrm{aBC}}$ & $7,96^{\mathrm{abE}}$ & $7,67^{\mathrm{bB}}$ \\
2 & $7,82^{\mathrm{aBC}}$ & $7,95^{\mathrm{aB}}$ & $7,82^{\mathrm{aB}}$ & $7,85^{\mathrm{aBCDE}}$ & $8,13^{\mathrm{aDE}}$ & $7,86^{\mathrm{aB}}$ \\
3 & $7,71^{\mathrm{bBCD}}$ & $7,66^{\mathrm{bB}}$ & $7,90^{\mathrm{bAB}}$ & $7,67^{\mathrm{aBCDE}}$ & $8,28^{\mathrm{aDE}}$ & $7,90^{\mathrm{bB}}$ \\
4 & $7,90^{\mathrm{abBC}}$ & $7,85^{\mathrm{abB}}$ & $7,88^{\mathrm{abAB}}$ & $7,55^{\mathrm{bDE}}$ & $8,11^{\mathrm{aE}}$ & $7,75^{\mathrm{abB}}$ \\
5 & $7,81^{\mathrm{bBCD}}$ & $7,81^{\mathrm{bB}}$ & $7,76^{\mathrm{bB}}$ & $7,64^{\mathrm{bDE}}$ & $8,77^{\mathrm{aDE}}$ & $5,40^{\mathrm{cC}}$ \\
6 & $7,56^{\mathrm{bCD}}$ & $7,57^{\mathrm{bCD}}$ & $7,76^{\mathrm{bB}}$ & $5,13^{\mathrm{bF}}$ & $9,22^{\mathrm{aCD}}$ & $7,90^{\mathrm{cB}}$ \\
7 & $7,29^{\mathrm{cCD}}$ & $9,08^{\mathrm{abAB}}$ & $7,98^{\mathrm{bCAB}}$ & $7,39^{\mathrm{cE}}$ & $9,59^{\mathrm{aBCD}}$ & $7,91^{\mathrm{bCB}}$ \\
8 & $7,49^{\mathrm{cCD}}$ & $8,85^{\mathrm{bAB}}$ & $7,88^{\mathrm{bCAB}}$ & $7,78^{\mathrm{bCDE}}$ & $9,91^{\mathrm{aABC}}$ & $8,45^{\mathrm{bcA}}$ \\
9 & $7,78^{\mathrm{bBCD}}$ & $10,34^{\mathrm{aA}}$ & $8,64^{\mathrm{bA}}$ & $8,04^{\mathrm{bBCDE}}$ & $10,47^{\mathrm{aAB}}$ & $8,41^{\mathrm{bA}}$ \\
10 & $7,52^{\mathrm{bCD}}$ & $8,20^{\mathrm{bAB}}$ & $8,14^{\mathrm{bAB}}$ & $8,02^{\mathrm{bBCDE}}$ & $10,71^{\mathrm{aA}}$ & $8,58^{\mathrm{bA}}$ \\
11 & $7,21^{\mathrm{cD}}$ & $6,97^{\mathrm{cB}}$ & $7,94^{\mathrm{cbAB}}$ & $8,02^{\mathrm{cbBCDE}}$ & $10,48^{\mathrm{aAB}}$ & $8,41^{\mathrm{bA}}$ \\
12 & $8,17^{\mathrm{bB}}$ & $7,86^{\mathrm{bB}}$ & $8,26^{\mathrm{bAB}}$ & $9,30^{\mathrm{aA}}$ & $8,15^{\mathrm{bDE}}$ & $8,58^{\mathrm{abA}}$ \\
\hline
\end{tabular}

Nota: Os resultados constituem médias de três repetições; as médias seguidas por letras minúsculas na horizontal oferecem a comparação dentro do período entre os tratamentos; e, por letras maiúsculas, a comparação dentro do tratamento entre os períodos de armazenamento. 


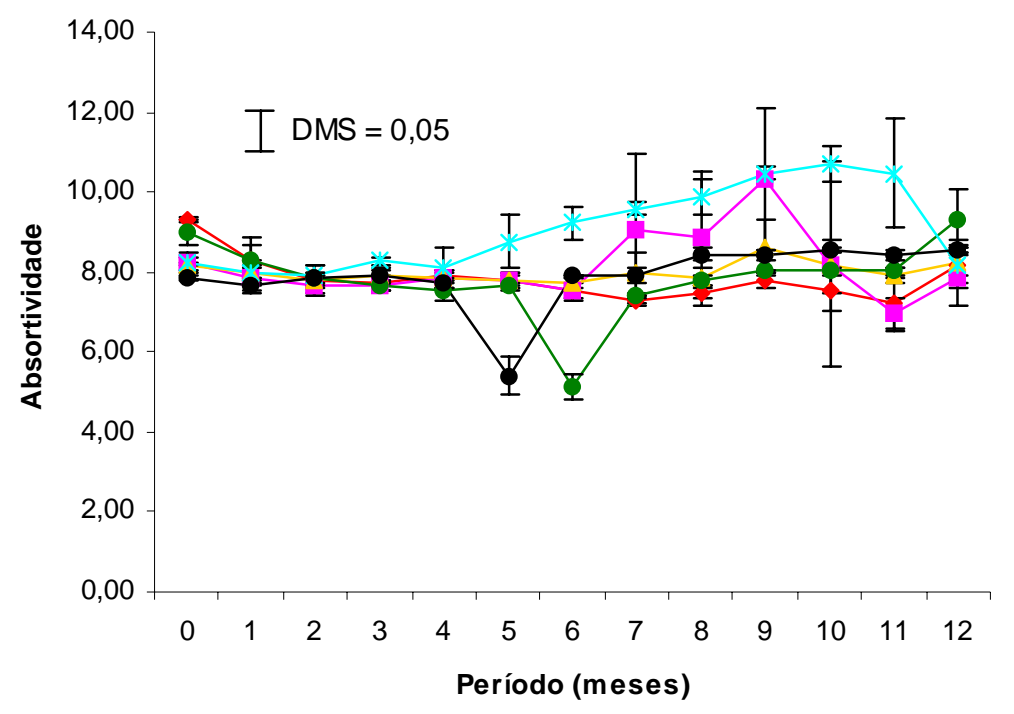

$\multimap$ PEAD SISIL $\multimap$ PEAD CISIL $\multimap$ VIDRO $\multimap$ PCTFE $*$ PVC $\multimap$ PVDC

Figura 11 - Absortividade em 232 nm no óleo de peixe encapsulado e acondicionado em diferentes tipos de embalagem por 12 meses. Cada ponto representa \pm um desvio padrão da média de três repetições.

CV (coeficiente de variação) $=7,25 \%$

PEAD S/Sil = frasco de polietileno de alta densidade sem sachê de sílica

PEAD $\mathrm{C} / \mathrm{Sil}$ = frasco de polietileno de alta densidade com sachê de sílica

VIDRO

PCTFE= "blister" com filme policlorotrifluoretileno

PVC = "blister" com filme policloreto de vinila

PVDC = "blister" com filme cloreto de polivinilideno

Assim como Shahidi (1995) já havia observado, que há uma correlação direta entre os valores de índice de peróxido e os de absortividade na faixa do ultravioleta em $232 \mathrm{~nm}$. Outros trabalhos desenvolvidos anteriormente no Laboratório de Óleos e Gorduras (Vieira, 1998; Almeida-Doria,1999; Siqueira, 
1998; Oliveira, 2003) também já haviam comprovado essa observação. Nesse experimento isso mais uma vez se comprova através da análise das Tabelas 2 e 3. O óleo encapsulado mantido nos "blisters" de PVC foi o que apresentou as maiores alterações na absortividade em $232 \mathrm{~nm}$, indicativo da ocorrência da conjugação das duplas ligações, decorrente da ressonância provocada na molécula do ácido graxo transformado em radical livre ou peroxila, nas fases iniciais do processo de oxidação do óleo. Também se observa que os filmes dos "blisters" ofereceram a menor proteção contra a oxidação em comparação com as embalagens rígidas.

A absortividade em $270 \mathrm{~nm}$ reflete a formação dos trienos conjugados e de compostos secundários durante o processo de oxidação que é proporcional à absorção de oxigênio no óleo (Rovellini et al., 1997). Dos resultados de absortividade em $270 \mathrm{~nm}$ (Tabela 4 e Figura 12) encontrados nos óleos de peixe, confirmou-se que a embalagem que menos proteção ofereceu ao óleo foi a de PVC. Ratificando comentários anteriores, destacaram-se as embalagens rígidas de PEAD com e sem sachê de silica, vidro como oferecendo boas propriedades de barreira.

Todas essas observações pontuais são confirmadas ao se observarem as curvas de varredura de absortividade dos óleos na faixa do ultravioleta do espectro apresentadas na Figura 13 a, b, c e d. Desde os três meses de armazenamento (Fig. 13a), destacaram-se as curvas das absortividades dos óleos em "blister" de PVC, com os valores mais altos, e em frasco rígido de PEAD com sílica, com os valores mais baixos, inclusive do que os do controle, indicando que o processo oxidativo foi retardado pela inserção das cápsulas no frasco. O comportamento de menor proteção oxidativa do óleo pelo PVC continuou a ser facilmente visualizado nas Figuras 13b e 13c, aos seis e nove meses, respectivamente. As cápsulas mantidas nos frascos de PEAD com e sem sílica foram as que mais preservaram os óleos da oxidação, demonstrado pelas curvas de valores mais baixos. Ao cabo dos doze meses de armazenamento (Fig. 13d) destacaram-se as embalagens rígidas de PEAD com 
e sem sílica, além do vidro, como as que apresentaram óleo com os valores mais baixos de absortividade, isto é, de melhor qualidade oxidativa. Os filmes de PVDC e PCTFE podem ser considerados de qualidade intermediária e o de PVC, como a menos recomendada para a preservação da qualidade do óleo de peixe.

Tabela 4. Absortividade em $270 \mathrm{~nm}$ do óleo de peixe encapsulado e acondicionado em diferentes tipos de embalagem por 12 meses.

TEMPO

TRATAMENTOS

\begin{tabular}{|c|c|c|c|c|c|c|}
\hline MÊS & PEAD S/SIL & PEAD C/SIL & VIDRO & PCTFE & PVC & PVDC \\
\hline 0 & $1,8^{\mathrm{aBCDE}}$ & $1,82^{\mathrm{aBCD}}$ & $1,79^{\mathrm{aBCD}}$ & $1,795^{\mathrm{aBCD}}$ & $1,84^{\mathrm{aBCD}}$ & $1,83^{\mathrm{aA}}$ \\
\hline 1 & $1,85^{\mathrm{aBCD}}$ & $1,82^{\mathrm{aBCD}}$ & $1,81^{\mathrm{aBC}}$ & $1,88^{\mathrm{AaB}}$ & $1,90^{\mathrm{aEF}}$ & $2,16^{\mathrm{aA}}$ \\
\hline 2 & $1,90^{\mathrm{aABC}}$ & $1,87^{\mathrm{abBC}}$ & $1,87^{\mathrm{abAB}}$ & $1,88^{\mathrm{abB}}$ & $1,88^{\mathrm{abEF}}$ & $1,84^{\mathrm{bA}}$ \\
\hline 3 & $1,83^{\mathrm{bD}}$ & $1,84^{\mathrm{abBC}}$ & $1,89^{a A B}$ & $1,83^{\mathrm{bBC}}$ & $1,89^{\mathrm{aEF}}$ & $1,87^{\mathrm{abA}}$ \\
\hline 4 & $1,91^{\mathrm{abAB}}$ & $1,88^{\mathrm{bcBC}}$ & $1,93^{\mathrm{aA}}$ & $1,84^{\mathrm{cBC}}$ & $1,93^{\mathrm{aEF}}$ & $1,87^{\mathrm{bcA}}$ \\
\hline 5 & $1,88^{\mathrm{aBCD}}$ & $1,87^{\mathrm{aBCD}}$ & $1,91^{\mathrm{aA}}$ & $1,78^{\mathrm{bDE}}$ & $1,95^{\mathrm{aE}}$ & $1,90^{\mathrm{aA}}$ \\
\hline 6 & $1,89^{\mathrm{abBCD}}$ & $1,88^{\mathrm{abBC}}$ & $1,94^{\mathrm{aA}}$ & $1,86^{\mathrm{bc}}$ & $1,95^{\mathrm{aE}}$ & $1,91^{\mathrm{abA}}$ \\
\hline 7 & $1,84^{\mathrm{bCD}}$ & $1,83^{\mathrm{bCD}}$ & $1,86^{\mathrm{bAB}}$ & $1,21^{\mathrm{cD}}$ & $2,01^{\mathrm{aD}}$ & $1,27^{\mathrm{cB}}$ \\
\hline 8 & $1,75^{\mathrm{dE}}$ & $1,95^{\mathrm{bA}}$ & $1,95^{\mathrm{bA}}$ & $1,78^{\mathrm{dC}}$ & $2,04^{\mathrm{aCD}}$ & $1,88^{\mathrm{cA}}$ \\
\hline 9 & $1,87^{\mathrm{bBCD}}$ & $1,86^{\mathrm{bCBC}}$ & $1,95^{\mathrm{bA}}$ & $1,91^{\mathrm{bB}}$ & $2,09^{\mathrm{aC}}$ & $1,89^{\mathrm{bA}}$ \\
\hline 10 & $1,92^{\mathrm{bcAB}}$ & $1,88^{\mathrm{CB}}$ & $1,92^{\mathrm{bcAB}}$ & $1,93^{\mathrm{bcB}}$ & $2,17^{\mathrm{aB}}$ & $1,96^{\mathrm{bA}}$ \\
\hline 11 & $1,96^{\mathrm{bA}}$ & $1,75^{\mathrm{CD}}$ & $1,91^{\mathrm{bAB}}$ & $1,91^{\mathrm{bB}}$ & $2,22^{\mathrm{aAB}}$ & $1,91^{\mathrm{bA}}$ \\
\hline 12 & $1,90^{\mathrm{CABC}}$ & $1,89^{\mathrm{cB}}$ & $1,90^{\mathrm{CABC}}$ & $2,23^{\mathrm{aA}}$ & $2,24^{\mathrm{aA}}$ & $1,99^{\mathrm{bA}}$ \\
\hline
\end{tabular}


Nota: Os resultados constituem médias de três repetições; as médias seguidas por letras minúsculas na horizontal oferecem a comparação dentro do período entre os tratamentos; e, por letras maiúsculas, a comparação dentro do tratamento entre os períodos de armazenamento.

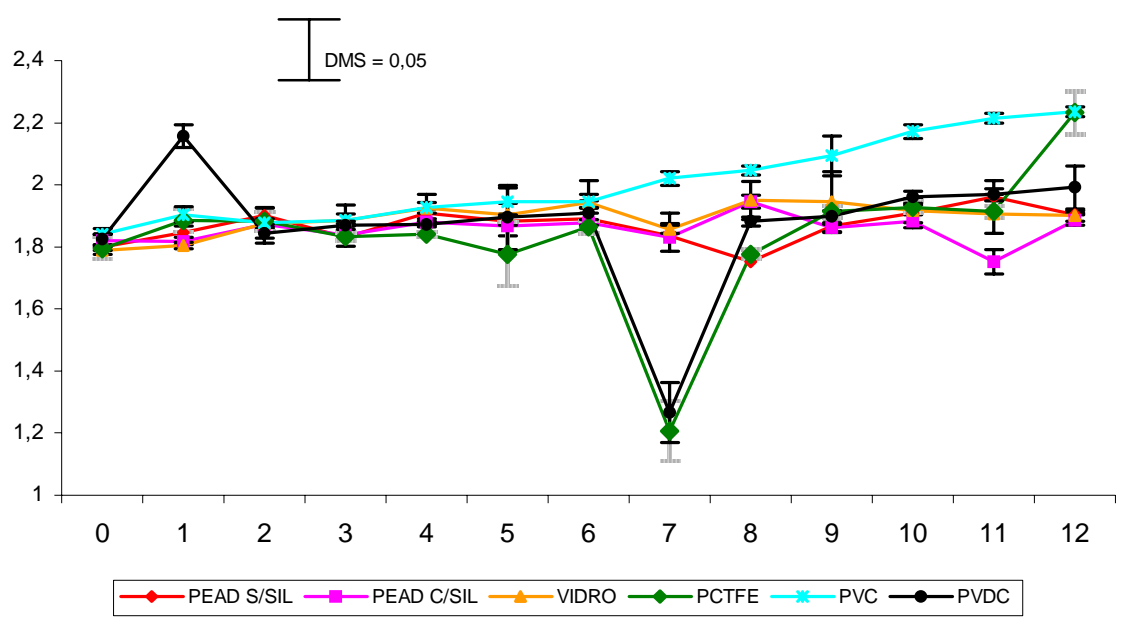

Figura 12 - Absortividade em $270 \mathrm{~nm}$ do óleo de peixe encapsulado e acondicionado em diferentes tipos de embalagem por 12 meses. Cada ponto representa \pm um desvio padrão da média de três repetições

$\mathrm{CV}=4,93 \%$

PEAD S/Sil = frasco de polietileno de alta densidade sem sachê de sílica

PEAD C/Sil = frasco de polietileno de alta densidade com sachê de sílica VIDRO

PCTFE= "blister" com filme policlorotrifluoretileno

PVC = "blister" com filme policloreto de vinila

PVDC = "blister" com filme cloreto de polivinilideno 


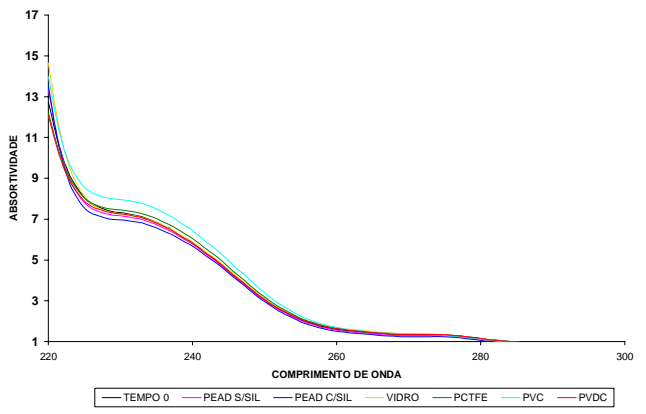

a)

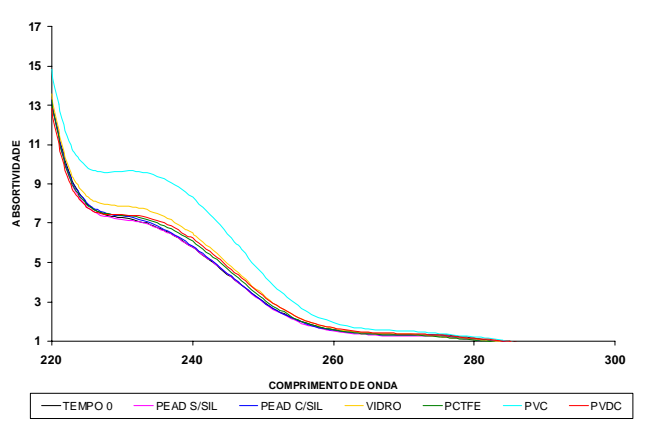

c)

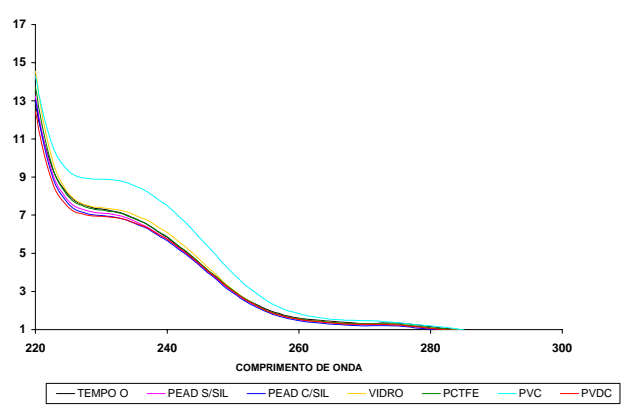

b)

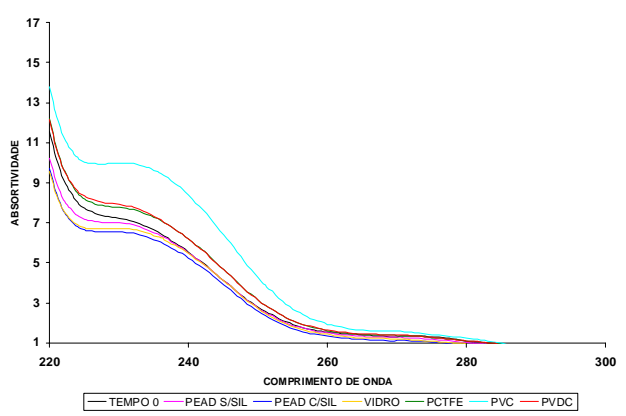

d)

Figuras 13 -Espectros de absortividade na faixa do ultravioleta do óleo de peixe encapsulado e acondicionado em diferentes tipos de embalagem por 3 (a), 6(b) meses, 9 (c) meses e 12 (d) meses.

Uma análise que auxilia no acompanhamento da estabilidade oxidativa do óleo de peixe é a cromatografia gasosa para quantificação dos ácidos graxos poliinsaturados, especificamente, os ácidos eicosapentaenóico e docosahexanóico, de funcionalidade já comentada. Como os processos oxidativos comprometem as duplas ligações e a sua distribuição na molécula, 
estágios adiantados de oxidação podem provocar perda desses ácidos graxos, reduzindo o valor nutricional do óleo de peixe.

Analisando a Figura 14, observa-se que ao longo do experimento a concentração de ácidos graxos em EPA e DHA manteve-se constante com o tempo de armazenamento. A maior perda desses ácidos graxos ocorreu no óleo dos "blisters" de PCTFE (Aclar) no $12^{\circ}$ período. Apesar de o Aclar ser citado por Allison et al. (2001) como um filme com boas barreiras, problemas com a termomoldagem e soldagem parecem ser a melhor explicação para essa notável redução de EPA e DHA no óleo nesse "blister" de PCTFE. O avançado estado oxidativo já tinha sido observado nas Tabelas 2, 3 e 4, através dos altos valores de índice de peróxido e E232 e 270 nm, respectivamente porém, mesmo assim, era inesperado esse comportamento. Reynolds (1989) cita que a concentração de DHA e EPA deve ser o equivalente de 18\% de EPA para 12\% de DHA. Também segundo Badolato et al. (1991), a relação aceita comercialmente no mercado prevê 180 mg de EPA para 120 de DHA sendo assim a embalagem de PCTFE não é adequada para acondicionar as cápsulas de óleo de peixe. 


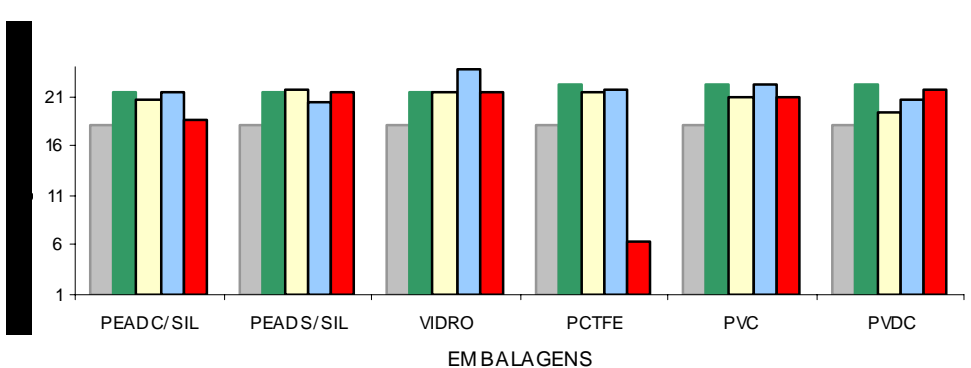

$\begin{array}{lllll}\square \text { TEMPO } 0 & \text { TEMPO } 1 & \text { वTEMPO 3 } & \text { व TEMPO 6 } & \text { व TEM PO } 12\end{array}$

a)

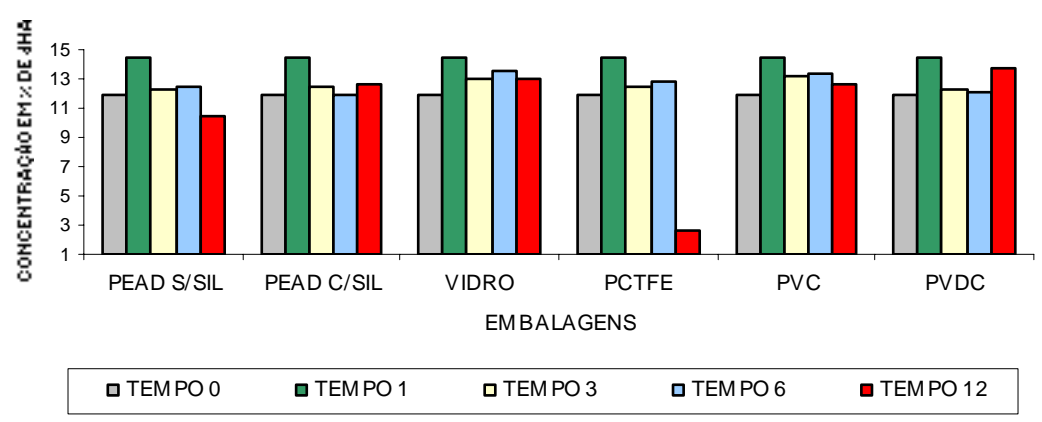

b)

Figura 14 - Concentração de ácido eicosapentaenóico (\%) (a) e docosahexaenóico (\%) (b) do óleo de peixe encapsulado e acondicionado em diferentes tipos de embalagem por 12 meses 


\section{CONCLUSÕES}

As embalagens de PEAD com e sem sachê de sílica demonstraram ter um bom efeito protetor contra a oxidação do óleo encapsulado nela armazenado. Além disso, confirmou-se a hipótese de que o filme de PVC não é um bom filme para embalagem de óleo encapsulado, pois o mesmo não oferece boas barreiras ao oxigênio e ao vapor de água. Já o filme PCTFE considerado com boas barreiras, provocou uma inesperada diminuição nas concentrações de EPA e DHA, resultante, provavelmente, do processo oxidativo, ocorrido por problemas com a termomoldagem e soldagem. 


\section{REFERÊNCIAS BIBLIOGRÁFICAS}

ACKMAN, R.G. Concerns for utilization of marine lipids and oils. Food Technology, v.42, n.5, p.151-155, 1988.

ACKMAN, R.G.; RATNAYAKE, W.M.N.; MACPHERSON, E.J. EPA and DHA contents of encapsulated fish oil products. Journal American Oil Chemists' Society, v.66, n.8, p. 1162-1164, 1989.

AHMAD, J.I. Omega three fatty acids - the key to longevity. Food Science and Technology Today, v.12, n.3, p.139-146, 1998.

ALLEN, D. Forming barrier materials for blister packages. Pharmaceutical Medical Packaging News, n.7, p.45-53, 1999

ALLINSON, J.G.; DANSEREAU, R.J.; SAKR, A. The effects of packaging on the stability of a moisture sensitive compound. International Journal of Pharmaceutics, n.221, p.49-56, 2001. 
ALMEIDA-DORIA, R.F. Ação antioxidante de extratos etanólicos de alecrim (Rosmarinus officinalis L.) e orégano (Origanum vulgare L.) em óleo de soja submetido à termoxidação e fotoxidação. Piracicaba, 1999. 71p. Dissertação (Mestrado) - Escola Superior de Agricultura "Luiz de Queiroz", Universidade de São Paulo.

AMERICAN OIL CHEMISTS' SOCIETY. Official methods and recommended practices. 5.ed. Champaign: AOCS, 1997. 2v.

AMIDON, G.E.; MIDDLETON, K.R.; Accelerated physical stability testing and long-term predictions of changes in the crushing strength of tablets stored in blister packages. International Journal of Pharmaceutics, n.45, p.79-89, 1988.

ANDREWS, J.S.; GRIFFIT, W.H.H.; MEAD, J.F.; STEIN, R.A. The introduction of intramolecular covalent cross-linkages into ichthyocol tropocollagen with monofunctional aldehydes. Journal Nutrition, v.70, n.199, p. ,1960.

BADOLATO, E.S.G.; CARVALHO, J.B.de; TAVARES,M.; AUED-PIMENTEL, S. Determinação dos ácidos eicosapentaenóico (EPA) e docosahexaenóico (DHA) em óleo de sardinha (Sardinella brasiliensis) brasileira e emsuplementos alimentares à base de óleo de sardinha. Revista Instituto Adolfo Lutz, v.1, n.1/2, p.75-81, 1991.

BANG, H. O.; DYERBERG, J. Personal reflections on the incidence of ischaemic heart disease in Oslo during the second world war. Acta Medica Scandinavia, v.210, p.245-248, 1981. 
BANKER, G.S.; RHODES, C.T. Modern pharmaceutics. New York: Marcel Dekker, p. 596, 1996.

BIMBO, P.; CROWTHER, J.B. Fish oils: processing beyond crude oil. Infofish International, v.6, n. p.20-25, 1991.

BOBBIO, P.A.; BOBBIO, F.O. Química do processamento de alimentos. São Paulo: Varela, 1992. cap.3, p.39-50: Lipídios.

BRASIL. Ministério da Saúde. Comissão Nacional de Normas e Padrões para Alimentos. Resolução $n^{0} 482$ - ANVS/MS de 23 de Setembro de 1999. Anexo 4. In: ASSOCIAÇÃO BRASILEIRA DAS INDÚSTRIAS DE ALIMENTAÇÃO. Compêndio da legislação de alimentos. São Paulo: ABIA, 2001. v.1/A, p.7.8 (00).

CARDINAL HEALTH BRASIL - http://www.cardinal.com. (20 Jul. de 2003).

CHO, S.Y.; MIYASHITA, K.; MIYAZAWA, T. et al. Autoxidation of ethyl eicosapentaenoate and docosahexaenoate. Journal of American Oil Chemists' Society, v.64, n.6, p.876-879, 1987.

COHEN, Z.; NORMAN, H.A., HEIMER, Y.M. Microalgae as a source of $\omega 3$ fatty acids. World Review of Nutrition and Dietetics, v.77, n.1 , p.1-31, 1995.

DYERBERG, J.; BANG, H.O. Haemostatic function and platelet polyunsaturated fatty acids in Eskimos. Nutrition, v.11, n.5, p.474-476, 1995.

EDER, K. The effects of a dietary oxidized oil on lipid metabolism in rats. Lipids, v.34, n.7, p.717-723, 1999. 
FARIA, J.A.F. A função da embalagem na estabilidade de óleos vegetais. Óleos e Grãos, n.6, p.50-52, 1991.

FARMER, E.H.; BLOOMFIELD, G.F.; SUNDARALINGAM, A.; SUTTON, D.A. The course and mechanism of autoxidation reaction in olefinic and polyfinic substances, including rubber. Transactions of the Faraday Society, v.38,p.348-356, 1942.

GUNSTONE, F.D. Chemical properties. In: GUNSTONE, F.D; HARWOOD, J.L.; PADLEY, F.B. (Ed.). The lipid handbook. London: Chapman \& Hall, 1994. cap.10, p.566-571.

GRUENWALD, G. Plastics: how structure determines properties. Munich: Hanser Publishers, 1993. cap.10, p.235-248: Chemical properties of polymeric materials.

GUGUMUS, F. Light stabilizers for thermoplastics. In: GÄCHTER, R.; MÜLLER, H. (Ed.). Plastics additives handbook. Munich: Hanser Publishers, 1990. cap.3, p.129-262.

HALLIWEL, B.; CHIRICO, S. Lipid peroxidation: its mechanism, measurement, and significance. American Journal Nutrition, v.57, Supplement 1, p.715s725s, 1993

HARTMAN, L.; LAGO, R.C.A. Rapid preparation of fatty acid methyl esters from lipids. Laboratory Practice, v.22, p.475-494, 1973. 
HAMILTON, R.J. The chemistry of rancidity in foods. In: ALLEN, J.C.; HAMILTON, R.J. Rancidity in foods. London: Black Academic \& Professional, 1994. cap.1, p.1-21.

HANLON, J.F. Handbook of package engineering. New York: McGraw Hill, 1971. p.3-45.

HU, M.L.; TAPPEL, A.L. Glutathione and antioxidants protect microsomes against lipid peroxidation and enzyme inactivation. Lipids, v.27, n.1, p.42-45, 1992.

HUNT, N. Blister packaging materials. Pharmaceutical \& Medical Packaging News. n.7, p.36-38, 1999. http://www.devicelink.com (22 Dec. 2004)

ILLIINGWORTH, D.; ULLMAN, D. Efects of omega-3 fatty acids on risk factors for cardiovascular diseases. In: LEES, R.S.; KAREL, M. Omega-3 fatty acids in health and disease. New York: Marcel Dekker, 1990. cap. 2 , p.39-69.

INTERNATIONAL UNION OF PURE AND APPLIED CHEMISTRY (IUPAC). Standard methods for the analysis of oils, fats and derivatives. 6.ed. Oxford: Pergamon Press, 1979. 170p.

KANG, J.X.; LEAF, A. The cardiac antiarrhythmic effects of polyunsaturated fatty acid. Lipids, v.31, Supplement 1, p.S41-S44, 1996.

KINSELLA, J.E. Food components with potential therapeutic benefits: the n-3 polyunsaturated fatty acids of fish oils. Food Technology, v.40, n.2, p.89-97, 1986. 
KINSELLA, J.E. Effects of polyunsaturated fatty acids on parameters related to cardiovascular disease. American Journal Cardiology, v. 60, p. 236, 1987.

KINSELLA, J.E.; LOKESH. B.; STONE, R.A. Dietary n-3 polyunsaturated fatty acids and amelioration of cardiovascular disease: possible mechanisms. American Journal Clinical Nutrition, v.52, n.1, p.1-28, 1990.

KINSELLA, J.E.; FRANKEL, E.; GERMAN, B.; KANNER, J. Possible mechanisms for the protective role of antioxidants in wine and plant foods. Food Technology, v.47, n.4, p.85-89, 1993.

KREMER, J.M.; BIGAUOETTE, J.; MICHALEK, A.V.; TIMCHALK, M.A.; LININGER, L.; RYNES, R.I.; HUYCK, C.;ZIEMINSKI, J. Effects of manipulation of dietary fatty acids on clinical manifestations of rheumatoid arthritis. The Lancet, v.1, p.185-187, 1985.

LANDS, W.E.M. Renewed questions about polyunsaturated fatty acids. Nutrition Reviews, v.44, n.6, p.189-195, 1986.

LANDS, W.E.M. Dose-response relationships for $\omega-3 / \omega-6$ effects In: SIMOPOULOS, A.P.; KIFER, P.R.; MARTIN, R.E.; BARLOW, S.M. (Ed.) Health effects of $\omega-3$ polyunsaturated fatty acids in seafoods. Basel: Karger, 1991. p.177-194. (World Review of Nutrition and Dietetics, v.66).

LEAF, A.; WEBER, P.C. Cardiovascular effects of $\omega 3$ fatty acids. European Journal Pharmacology, v.341, p.145-152, 1998.

LINKO, Y.Y.; HAYAKAWA, K. Docosahexaenoic acid: a valuable nutraceutical? Trends in Food Science and Technology, v.7, n.2, p.59-63, 1996. 
LOCKHART, H.; PAINE, F.A. Packaging of pharmaceuticals and healthcare products. London: Blackie Academic \& Professional, 1996. 211p.

LOSSONCZY, T.O. The effect of a fish diet on serum lipids in healthy human subjects. American Journal of Clinical Nutrition, v.31, n.8, p.1340-1346, 1978.

MOUNTS, T.L.Codex fats and oils panel meets in London. Inform v.5, n.1, p.96, 1994.

NAWAR, W. Lipids. In: FENNEMA, O.R. (Ed.) Food chemistry. New York: Marcel Dekker Inc., 1985. p.139-244.

OLIVEIRA, J.T.G.S.B. Melhor dosagem e dose econômica de TBHQ nos óleos de milho e canola. Piracicaba, 2003. 75 p. Dissertação (Mestrado) - Escola Superior de Agricultura "Luiz de Queiroz", Universidade de São Paulo.

OLIVEIRA, L.M. Embalagens para produtos farmacêuticos. Informativo Centro de Tecnologia e Embalagens de Alimentos, v.9, n.3, p.3 -6, mai./jun. 1997.

ORTIZ, S. A.; JAIME, S.B.M.; BORDIN, M.R.; GARCIA. A.E. Embalagens de vidro para produtos farmacêuticos. Campinas: CETEA/ITAL, 2000.154 p.

ORTIZ, S.A. Principais tendências de embalagem para produtos farmacêuticos. Campinas: CETEA/ITAL, 2000. 273p.

PASCAL, M.A.; HARTE, B.R.; GIACIN, J.R.; GRAY, J.I. Decreasing lipid oxidation in soybean oil by a UV absorber in the packaging material. Journal of Food Science, v.60, n. 5, p. 1116-1119, 1995. 
PEGG, R.B.; SHAHIDI, F. Nitrite curing of meat: the $\mathbf{n}$-nitrosamine problem and nitrite alternatives. Connecticut: Food \& Nutrition Press, 2000. cap.4, p.67-104: Oxidative stability of meat lipids.

PRISTA, N.L. Tecnica farmacêutica e farmácia galênica. Lisboa: Fundação Calouste Gulbenkian, 1992. v.1, cap.7, p.591-949: formas farmacêuticas obtidas por divisão mecânica.

PILCHIK, R. "Pharmaceutical blister packaging, part I: rationale and materials", Pharmaceutical Technology, v.24, n.11, p.68-78, 2000.

REDDY, B.S.; MARUYAMA, H. Effect of dietary fish oil on azoxymethaneinduced colon carcinogenesis in male F344 rats. Cancer Research, v. 46, n.7, p. 3367-3370, jul. 1986.

REYNOLDS, J.E.F. (Ed.) Martindale: the extra pharmacopéia. London: The Pharmaceutical Press, 1989. p.1896.

ROVELLINI, P.; CORTESI, N.; FEDELI, E. Ossidazione dei lipid. La Rivista Italiana delle Sostanze Grasse, v.74, n.5, p.181-189, 1997.

SARANTÖPOULOS, C.I.G.L.; OLIVEIRA, L.M. de; PADULA, M. et al. Embalagens plásticas flexíveis: principais polímeros e avaliação de propriedades. Campinas: CETEA/ITAL, p.267, 2002.

SAS INSTITUTE. SAS: user's guide. Version 6.11. 4. ed. Cary: SAS Institute, 1996. $956 p$. 
SELLMAYER, A.; HRBOTICKY, N.; WEBER, P.C. Lipids in vascular function. Lipids, v.34, p.13-18, 1999.

SHAHIDI, F. Stability of fats and oils. In: LATIN AMERICAN CONGRESS AND EXHIBIT ON FATS AND OILS PROCESSINGS, 6., Campinas, 1995. Proceedings. Campinas: Sociedade Brasileira de Óleos e Gorduras, 1995. p.47-54.

SHAHIDI, F. Lípidos y proteínas funcionales del pescado In: MAZZA, G. Alimentos funcionales. Zaragoza: Editorial Acribia, 1998. cap.12, p.381-401

SHIMADA, Y.; ROOS, Y.; KAREL, M. Oxidation of methyl linoleate encapsulated in amorphous lactose-based food model. Journal of Agriculture Food Chemistry, v.39, p.637-641, 1991.

SHUKLA, V.K.S.; PERKINS, E.G. The presence of oxidative polymeric materials in encapsulated fish oils. Lipids, v.26, n.1, p.23-26, 1991.

SHUKLA, V.K.S.; PERKINS, E.G. Rancidity in encapsulated health-food oils. Inform, v.9, n.10, p.955-961, 1998.

SIMIC, M.G.; JOVANOVIC, V.S.; NIKI, E. Mechanisms of lipid oxidative processes and their inhibition. In: ALLEN, J.A. Lipid oxidation in food. New York: American Chemical Society, 1992, cap.2, p.14-32.

SIMOPOULAS, A.P.; KIFER, R.R.; MARTIN, R.E. (Ed.). Health effects of polyunsaturated fatty acids in seafoods. Orlando: Academic Press,1986. $473 p$. 
SIQUEIRA, F.M. Estabilidade oxidativa de óleos de soja, milho e canola. Piracicaba, 1998. 91p. Dissertação (Mestrado) - Escola Superior de Agricultura "Luis de Queiroz", Universidade de São Paulo.

SPECTOR, A.A. Essentiality of fatty acids. Lipids, v.34, Supplement 1, p.s1-s3, 1999.

STANLEY, J.P. Soft gelatin capsules. In: LACHMAN, L.; LIEBERMAN, H.; KANIG, J.L. The theory and practice of industrial pharmacy. Philadelphia: Lea \& Febiger, 1986. cap.2, p.683-705.

STAZIONE SPERIMENTALE PER LE INDUSTRIE DEGLI OLI E DEI GRASSI. Norme italiane per il controllo dei grassi e derivati. 3.ed. Milano: Stazione Sperimentale per le Industrie Degli Oli e Dei Grassi. 1976. p.

STROM, A.; JENSEN, R.A. Mortality from circulatory diseases in Norway 19401945. Lancet, v.257, p.126-129, 1951.

SUBSTITUIÇÃO dos filmes de PVC e laminados de alumínio. Pharmaceutical Technology, v.22, n.4, p.22-31, April 1998.

TAWFIK, M.S.; HUYGHEBAERT, A. Interaction of packaging materials and vegetable oils: oil stability. Food Chemistry, v.64, n.4, p.451-459, 1999.

UNITED STATES PHARMACOPEIA. USP 24. ed Rockville: US Pharmacopeial Convention, 2000. 
VEIS, A.; DRAKE, M. P. The introduction of intramolecular covalent crosslinkages into ichthyocol tropocollagen with monofunctional aldehydes Journal of Biological Chemistry, v.238, n.6, p.2003-2011, 1963.

VIEIRA, T.M.F.S. Estabilidade oxidativa de óleos vegetais refinados: efeito do aquecimento por microondas. Piracicaba, 1998. 70p. Dissertação (Mestrado)

- Escola Superior de Agricultura "Luiz de Queiroz", Universidade de São Paulo.

ZIBOH, V.A.; COHEN, K.A.; ELLIS, C.N.; MILLER, C. Effects of dietary supplementation of fish oil on neutrophil and epidermal fatty acids: modulation of clinical source of psoriatic subjects. Archives of Dermatology, v.122, p.1277-1282, 1986. 